\title{
Auroral and sub-auroral phenomena: an electrostatic picture
}

\author{
J. De Keyser and M. Echim \\ Belgian Institute for Space Aeronomy (BIRA-IASB), Ringlaan 3, 1180 Brussels, Belgium \\ Received: 30 October 2009 - Accepted: 15 February 2010 - Published: 23 February 2010
}

\begin{abstract}
Many auroral and sub-auroral phenomena are manifestations of an underlying magnetosphere-ionosphere coupling. In the electrostatic perspective the associated auroral current circuit describes how the generator (often in the magnetosphere) is connected to the load (often in the ionosphere) through field-aligned currents. The present paper examines the generic properties of the current continuity equation that characterizes the auroral circuit. The physical role of the various elements of the current circuit is illustrated by considering a number of magnetospheric configurations, various auroral current-voltage relations, and different types of behaviour of the ionospheric conductivity. Based on realistic assumptions concerning the current-voltage relation and the ionospheric conductivity, a comprehensive picture of auroral and sub-auroral phenomena is presented, including diffuse aurora, discrete auroral arcs, black aurora, and subauroral ion drift. The electrostatic picture of field-aligned potential differences, field-aligned currents, ionospheric electric fields and plasma drift, and spatial scales for all these phenomena is in qualitative agreement with observations.
\end{abstract}

Keywords. Magnetospheric physics (Auroral phenomena; Current systems; Magnetosphere-ionosphere interactions)

\section{Introduction}

The present paper addresses auroral phenomena that result from a tight coupling between the magnetosphere and the ionosphere. Underlying these phenomena is an electric circuit that consists of a generator that acts as a current or voltage source, a load in which energy is dissipated, and electrical connections between the generator and the load. This circuit implies currents that flow across magnetic field lines in the magnetosphere, that flow up and/or down along mag-

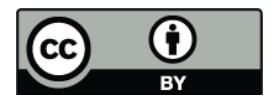

Correspondence to: J. De Keyser (johan.dekeyser@aeronomie.be) netic field lines between magnetosphere and ionosphere, and that close across magnetic field lines in the conducting ionosphere (see Fig. 1). The discussion is limited here to quasistatic situations, in which a fairly long-lived equilibrium is established (a time scale of minutes).

It is assumed that the current circuit associated with major auroral phenomena contains a magnetospheric generator and an ionospheric load, i.e., the magnetospheric electrostatic potential is given and the ionospheric potential has to be determined from the coupling. The generator must be able to sustain the magnetospheric electric fields on a time scale that is long enough to set up the ionospheric configuration. It has been argued that, for instance, discrete arcs and subauroral ion drift layers are indeed powered by such magnetospheric generators (e.g., Roth et al., 1993; De Keyser et al., 1998; Echim et al., 2007, 2009). Although one cannot exclude the possibility of an ionospheric generator, as might be the case for polar cap arcs and theta aurorae (Zhu et al., 1993, 2005), that situation is not considered here. As the current continuity condition at the heart of the electrostatic description does not distinguish between both situations, much of the discussion in this paper applies to either case.

A magnetospherically driven current circuit is characterized by four ingredients:

1. the magnetic field geometry, indicating how the highand low-altitude configurations map onto each other;

2. the nature of the field-aligned currents, as characterized by the auroral current-voltage relation that expresses how charged particles flow between ionosphere and magnetosphere as a consequence of the electric potential difference between both;

3. the electric structure of the generator, as quantified by the magnetospheric electric potential;

4. the conductivity of the ionosphere, which expresses how the (horizontal) ionospheric current flows in response to spatial variations of the ionospheric potential.

Published by Copernicus Publications on behalf of the European Geosciences Union. 


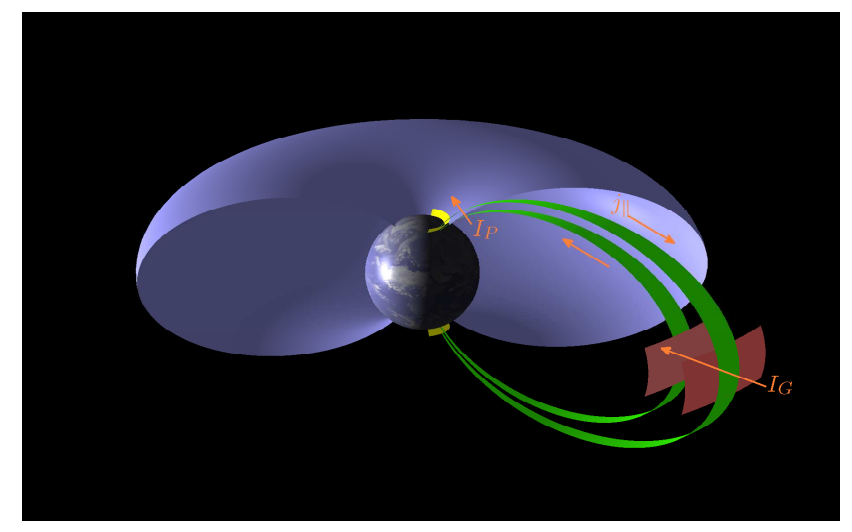

Fig. 1. Sketch of the current system above auroral features. The current $I_{\mathrm{G}}$ maintained by the generator closes via field-aligned currents $j_{\|}$and a horizontal Pedersen current $I_{\mathrm{P}}$ through the load in the ionosphere.

The mapping between high- and low-altitude structures is considered here to be given, although in practice it can be very hard to establish, especially when tracing magnetic field lines that are near the open/closed field line boundary, and when the generator is far from Earth. This paper focuses on the role of the other three ingredients. Section 2 sets the stage by introducing the continuity equation. Several current-voltage relations are presented in Sect. 3, and their physical importance is illustrated in Sect. 4 for a simple magnetospheric electric field configuration. Variations in the magnetospheric generator plasma manifest themselves as changes in the current-voltage relation parameters; a typical example is described in Sect. 5. The role of the magnetospheric potential profile, the second ingredient, is explored in Sect. 6. The importance of the ionospheric conductivity, the third ingredient, is highlighted in Sect. 7. The effects of the three ingredients are illustrated by means of model problems. The paper includes a discussion of the existence and uniqueness of solutions of the current continuity equation (Sect. 8) and proposes a technique for solving this equation numerically (Sect. 9). The paper concludes with a summary of the main features of the electrostatic description in the form of a comprehensive classification of auroral and sub-auroral phenomena that is compatible with observations.

\section{The current continuity equation}

Lyons $(1980,1981)$ studied a one-dimensional model of the auroral current circuit. Let $x$ be the horizontal coordinate perpendicular to the auroral structure (e.g., a discrete arc), measured at ionospheric altitude, positive in the poleward direction. With each position $x$, a high-altitude position $\hat{x}$ in the magnetosphere can be associated by following the magnetic field line. The function $\hat{x}(x)$ represents the mapping between ionosphere and magnetosphere due to the magnetic field line geometry. Using this mapping, all spatial variations can be expressed in terms of the ionospheric coordinate $x$. Lyons' analysis starts from a given magnetospheric electric potential distribution $\hat{\phi}(\hat{x})=\hat{\phi}(\hat{x}(x))$ in a frame that corotates with the ionosphere. Current continuity at the top of the ionosphere,

$$
\frac{\mathrm{d}}{\mathrm{d} x} I_{\mathrm{P}}=-j_{\|},
$$

states that the divergence of the height-integrated horizontal ionospheric Pedersen current $I_{\mathrm{P}}$ is balanced by the fieldaligned current $j_{\|}$; for the sake of simplicity, these are assumed to be vertical. Hall currents are ignored here. $I_{\mathrm{P}}$ is measured positive towards the pole, while $j_{\|}$is taken positive if the current is upward. The height-integrated Pedersen conductivity $\Sigma_{\mathrm{P}}$ relates the Pedersen current to the ionospheric potential by

$I_{\mathrm{P}}=-\Sigma_{\mathrm{P}} \frac{\mathrm{d}}{\mathrm{d} x} \phi$

this equation is nothing else than the classical Ohm's Law in a resistive medium, which relates the potential drop along the conducting medium $(\mathrm{d} \phi / \mathrm{d} x)$ to the current flowing through that medium $\left(I_{\mathrm{P}}\right)$. The height-integrated approach is valid as long as the current balance is made at the top of the ionosphere, since it is assumed that no horizontal currents flow above that altitude (Atkinson, 1970). The steady current continuity equation therefore is

$\frac{\mathrm{d}}{\mathrm{d} x}\left(\Sigma_{\mathrm{P}} \frac{\mathrm{d}}{\mathrm{d} x} \phi\right)=j_{\|}$.

In general both $j_{\|}$and $\Sigma_{\mathrm{P}}$ may be spatially varying. Depending on the level of sophistication of the model, they may depend on the field-aligned potential difference $\Delta \phi=\phi-\hat{\phi}$ and hence on the solution $\phi$ itself: The model then becomes nonlinear.

\section{Current-voltage relations}

The current-voltage relation is the result of the physical description of the motion and acceleration of the electric charge carriers, both positive and negative, originating in the ionosphere or in the magnetosphere. At the same time a phenomenological approach to modelling the current-voltage relation can be taken, allowing a more empirical study of the current circuit.

A fundamental insight is that, depending on the sign of the charge of the particles, a larger potential difference between ionosphere and magnetosphere tends to promote or suppress the field-aligned motion of the particles, and hence the fieldaligned currents (e.g. Knight, 1973; Evans, 1974). The current contributed by each species $s$ should therefore obey

$\frac{\mathrm{d} j \| s}{\mathrm{~d} \Delta \phi} \geq 0$. 
The current-voltage relation $j_{\| s}(\Delta \phi)$ is usually nonlinear, in particular near $\Delta \phi \approx 0$ where there is a rather abrupt transition between promotion and suppression of parallel motion of the charge carriers. The $\Delta \phi>0$ and $<0$ cases therefore are treated separately. In the region where a significant nonzero current flows, $j_{\| s}$ tends to be a smooth function of $\Delta \phi$ so that a Taylor series expansion around a typical potential difference $\Delta \phi_{0}$ is possible:

$$
\begin{aligned}
j_{\| s}(\Delta \phi)= & j_{\| s}\left(\Delta \phi_{0}\right)+\frac{\mathrm{d} j_{\| s}\left(\Delta \phi_{0}\right)}{\mathrm{d} \Delta \phi} \Delta \phi \\
& +\frac{1}{2} \frac{\mathrm{d}^{2} j_{\| s}\left(\Delta \phi_{0}\right)}{\mathrm{d} \Delta \phi^{2}}(\Delta \phi)^{2}+\ldots
\end{aligned}
$$

Truncating this expansion leads to a polynomial approximation of $j_{\| s}$. The case of a linear approximation is addressed first, with or without the (often small) constant term. Then the nonlinear case is treated, but rather than going to higherorder approximations, the domain of the function is subdivided and two different linear approximations are used depending on whether $|\Delta \phi|$ exceeds a treshold $\Delta \phi^{*}$.

The simplest model is the linear current-voltage relation without constant term, which gives, for positive magnetospheric/negative ionospheric species,

$j_{\| s}= \begin{cases}0, & \Delta \phi \geq 0, \\ K_{s} \Delta \phi, & \Delta \phi<0,\end{cases}$

and for negative magnetospheric/positive ionospheric species

$j_{\| s}= \begin{cases}K_{s} \Delta \phi, & \Delta \phi \geq 0 \\ 0, & \Delta \phi<0 .\end{cases}$

The proportionality factor $K_{S}$ is often called the Knight constant. Following Eq. (4), $K_{s}$ should be positive. The Knight constant describes how the parallel current grows with the field-aligned potential drop that provokes it. It can be deduced from a nonlinear current-voltage relation (Lyons, 1980) as $K_{S}=\mathrm{d} j_{\| s} / \mathrm{d} \Delta \phi$ in the $\Delta \phi$ interval of interest. If $K_{S}$ is small, the species does not contribute much to the parallel current, unless $\Delta \phi$ can become large. If $K_{s}$ is large, however, already a small parallel potential difference is able to create a strong parallel current and this will have a decisive influence on the overall current circuit. Consider, for example, the case of electrons of magnetospheric origin. A potential difference $\Delta \phi>0$ accelerates these electrons downward, giving rise to an upward current $j_{\| s}$. If the potential difference is negative, these electrons encounter an electrostatic barrier and cannot reach the ionosphere, so that $j_{\| s}=0$. This is a major simplification since in reality the magnetic mirror force and the nonzero thermal energy of the generator particles also play a role. The Knight constant depends on source population properties, such as density and temperature, as well as on the geometric mapping between magnetosphere and ionosphere (Lyons, 1980). If each species produces a field-aligned cur- (a)

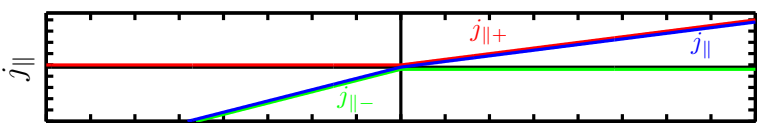

(b)

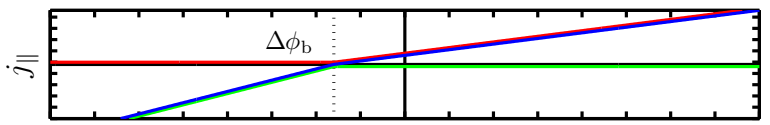

(c)

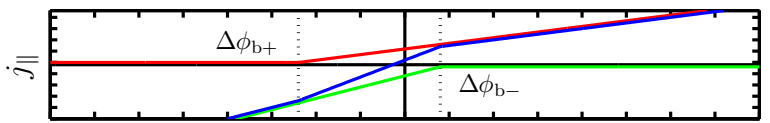

(d)

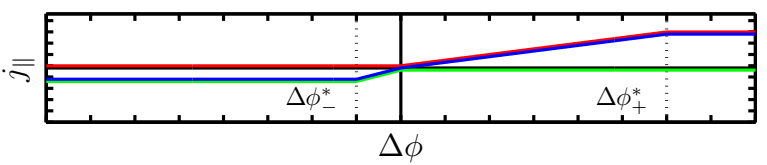

Fig. 2. Different current-voltage relations $j_{\|}(\Delta \phi)$ for the auroral current system (blue), with upward (red) and downward (green) currents $j_{\| \pm}$carried by magnetospheric and ionospheric particles. (a) Current linearly proportional to $\Delta \phi$ for both upward and downward current regions. (b) Linear current-voltage relation with a bias potential $\Delta \phi_{\mathrm{b}}$. (c) Linear relation with different bias $\Delta \phi_{\mathrm{b} \pm}$ for upand downward currents. (d) Current-voltage relation with current limits; the limit for downward currents is fairly low and starts from a small $\Delta \phi_{-}^{*}$, while the linear relation can be maintained for upward currents up to a much larger treshold $\Delta \phi_{+}^{*}$.

rent of the type discussed above, the total field-aligned current is

$j_{\|}=\sum_{s} j_{\| s}= \begin{cases}K_{+} \Delta \phi, & \Delta \phi \geq 0, \\ K_{-} \Delta \phi, & \Delta \phi<0,\end{cases}$

where $K_{+}$and $K_{-}$are the sums of the Knight constants of the positively and negatively charged species, as depicted in Fig. 2a.

A more realistic current-voltage relation might be characterized by $j_{0 s}=j_{\| s}(0) \neq 0$. This is the case for hot magnetospheric populations, which may precipitate even in the absence of a field-aligned potential difference as the particles in the loss cone mirror at ionospheric altitudes. A nonzero partial current at zero potential difference can also be created by particles that evaporate from the ionosphere. Expressions (5) and (6) are then modified, so that for positive magnetospheric/negative ionospheric species

$j_{\| s}= \begin{cases}0, & \Delta \phi \geq \Delta \phi_{\mathrm{bs}}, \\ K_{s} \Delta \phi+j_{0 s}, & \Delta \phi<\Delta \phi_{\mathrm{b} s},\end{cases}$

and for negative magnetospheric/positive ionospheric species

$j_{\| s}= \begin{cases}K_{s} \Delta \phi+j_{0 s}, & \Delta \phi \geq \Delta \phi_{\mathrm{bs}}, \\ 0, & \Delta \phi<\Delta \phi_{\mathrm{bs}},\end{cases}$

where $\Delta \phi_{\mathrm{b} s}=-j_{0 s} / K_{s}$ represents a bias potential. If this bias potential is the same for all species, the total current is

$j_{\|}= \begin{cases}K_{+} \Delta \phi+j_{0+}, & \Delta \phi_{\mathrm{b}} \leq \Delta \phi, \\ K_{-} \Delta \phi+j_{0-}, & \Delta \phi<\Delta \phi_{\mathrm{b}},\end{cases}$ 
where $j_{0+}$ and $j_{0-}$ are the sums of the zero-potential currents $j_{0 s}$ of all positive and negative species, respectively, so that $j_{0 \pm}=-K_{ \pm} \Delta \phi_{\mathrm{b}}$ (see Fig. 2b). If, however, all negatively charged species have a bias potential $\Delta \phi_{\mathrm{b}-} \geq 0$ while all positive species have a different bias $\Delta \phi_{\mathrm{b}+} \leq 0$, the overall current-voltage relation becomes

$j_{\|}= \begin{cases}K_{+} \Delta \phi+j_{0+}, & \Delta \phi_{\mathrm{b}-} \leq \Delta \phi, \\ K_{0} \Delta \phi+j_{0}, & \Delta \phi_{\mathrm{b}+} \leq \Delta \phi<\Delta \phi_{\mathrm{b}-}, \\ K_{-} \Delta \phi+j_{0-}, & \Delta \phi<\Delta \phi_{\mathrm{b}+},\end{cases}$

with $j_{0 \pm}=-K_{ \pm} \Delta \phi_{\mathrm{b} \pm}, j_{0}=j_{0+}+j_{0-}$, and

$K_{0}=\frac{j_{0+}-j_{0-}+K_{+} \Delta \phi_{\mathrm{b}-}-K_{-} \Delta \phi_{\mathrm{b}+}}{\Delta \phi_{\mathrm{b}-}-\Delta \phi_{\mathrm{b}+}}$

(see Fig. 2c). While the individual $j_{0 s}$ might be considerable, $j_{0}$ tends to be smaller because of a partial cancellation of the upward and downward current contributions. In general, if all $\Delta \phi_{\mathrm{bs}}$ are different, the current-voltage relation remains continuous and piecewise linear.

A deviation from the linear behaviour is expected for large field-aligned potential differences: When a large current has to flow, the reservoirs that supply these charged particles may become depleted. In order to achieve a dynamic equilibrium, these reservoirs must be replenished, but the speed with which that can be done must somehow be limited. For large $|\Delta \phi|$, one therefore expects

$\left|\frac{\mathrm{d}^{2} j_{\| s}}{\mathrm{~d} \Delta \phi^{2}}\right| \leq 0$

expressing that it becomes progressively harder to sustain large currents. Such a current limiting effect may play a role in the generator; depending on the generation mechanism, there may be limitations to the maximum current that can be produced. If the generator is a plasma interface (Roth et al., 1993; De Keyser, 1999; Echim et al., 2007, 2009), there must be a current $I_{\mathrm{G}}$ across the sheet, which could be produced by cross-field diffusion or by a small normal magnetic field component (De Keyser, 1999). A current limiting effect might also apply to ionospheric electrons. A negative $\Delta \phi<0$ could easily accelerate ionospheric electrons upward and give rise to a large $K_{-}$, especially since magnetic mirroring would not be an issue as for precipitating magnetospheric electrons (Carlson et al., 1998). However, this may be limited by the ambipolar electric field that tends to retain the electrons in the ionosphere (see, e.g., Newman et al., 1986; Vedin and Rönnmark, 2005); Temerin and Carlson (1998) argue that $K_{-} \geq K_{+}$. Also, if the ionospheric electrons are becoming depleted, the ionospheric dynamics start to resupply electrons, but that happens on a longer timescale so that the conductivity is reduced considerably. A simple model for a current-voltage relation that includes this current limiting effect is, for positive magnetospheric/negative ionospheric species,

$j_{\| s}= \begin{cases}0, & \Delta \phi \geq 0, \\ K_{s} \Delta \phi, & \Delta \phi_{s}^{*} \leq \Delta \phi<0, \\ K_{s} \Delta \phi_{s}^{*}=j_{s}^{*}, & \Delta \phi<\Delta \phi_{s}^{*},\end{cases}$

and for negative magnetospheric/positive ionospheric species

$j_{\| s}= \begin{cases}K_{s} \Delta \phi_{s}^{*}=j_{s}^{*}, & \Delta \phi_{s}^{*} \leq \Delta \phi, \\ K_{s} \Delta \phi, & 0 \leq \Delta \phi<\Delta \phi_{s}^{*}, \\ 0, & \Delta \phi<0,\end{cases}$

where $\Delta \phi_{s}^{*}$ is the potential at which the partial current saturates. If the limits $\Delta \phi_{+}^{*}$ and $\Delta \phi_{-}^{*}$ are the same for all positive and negative species, respectively, the overall current-voltage relation is

$j_{\|}= \begin{cases}K_{+} \Delta \phi_{+}^{*}=j_{+}^{*}, & \Delta \phi_{+}^{*} \leq \Delta \phi, \\ K_{+} \Delta \phi, & 0 \leq \Delta \phi<\Delta \phi_{+}^{*}, \\ K_{-} \Delta \phi, & \Delta \phi_{-}^{*}<\Delta \phi<0, \\ K_{-} \Delta \phi_{-}^{*}=j_{-}^{*}, & \Delta \phi \leq \Delta \phi_{-}^{*}\end{cases}$

(see Fig. 2d). If the $\Delta \phi_{s}^{*}$ do not coincide, the current-voltage relation is more difficult to express, but it remains a piecewise linear and continuous relation that satisfies Eq. (12).

More elaborate physically motivated kinetic currentvoltage relations have been discussed by various authors (e.g., Lemaire and Scherer, 1971, 1973; Knight, 1973; Evans, 1974; Fridman and Lemaire, 1980; Pierrard, 1996; Vedin and Rönnmark, 2004, 2005; Pierrard et al., 2007). These usually involve expressions for $j_{\| s}$ that depend nonlinearly on $\Delta \phi$, on the properties of the source populations, and on the magnetic field mapping. An underlying assumption of most of these current-voltage relations is that the particles do not encounter any local phase space barriers in their field-aligned motion, i.e., that both the magnetic field strength and the electric potential vary monotonically along the field lines.

In reality, the partial currents are not independent as quasineutrality must be maintained along field lines. Ambipolar electric fields are created, which imply a non-monotonic distribution of the electric potential along the field lines (Lemaire and Scherer, 1973; Temerin and Carlson, 1998; Vedin and Rönnmark, 2005), and which can form effective potential barriers for the current-carrying particles, possibly leading to trapped particle populations (Newman et al., 1986). The charge distribution along a field line is also affected by gravitational effects due to the mass difference of upwelling ionospheric ions and electrons, and by the difference in mirroring altitudes of magnetospheric ions and electrons (Schriver, 1999; Hultqvist, 2002).

\section{Converging and diverging electric fields}

Magnetospheric electric fields are very often associated with plasma convection. Two adjacent plasmas flowing with 
(a)
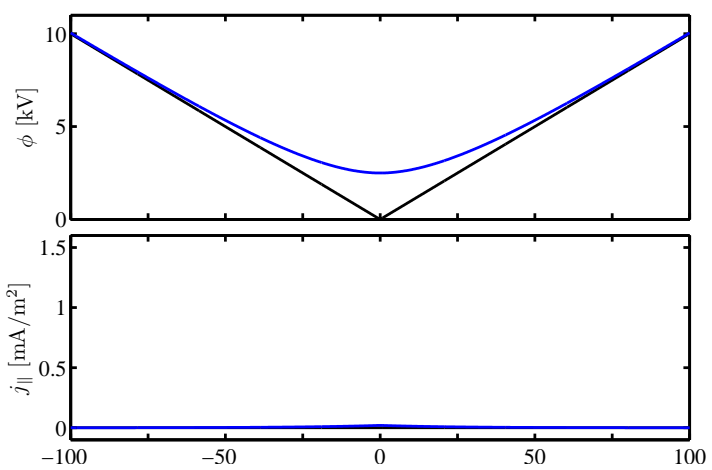

(b)

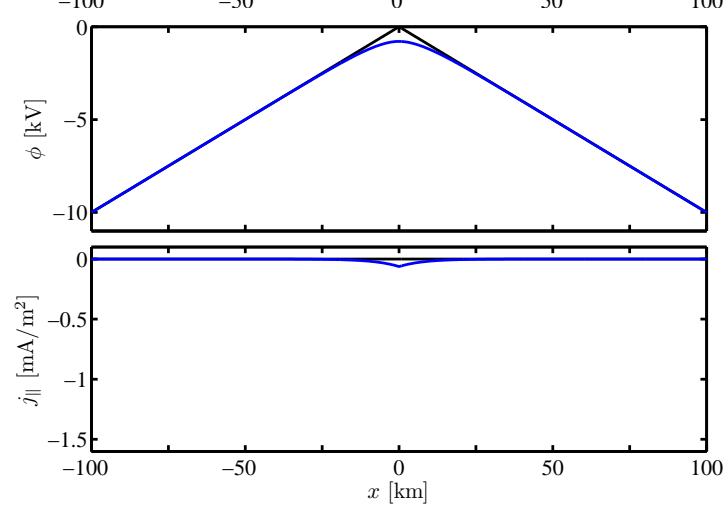

(c)
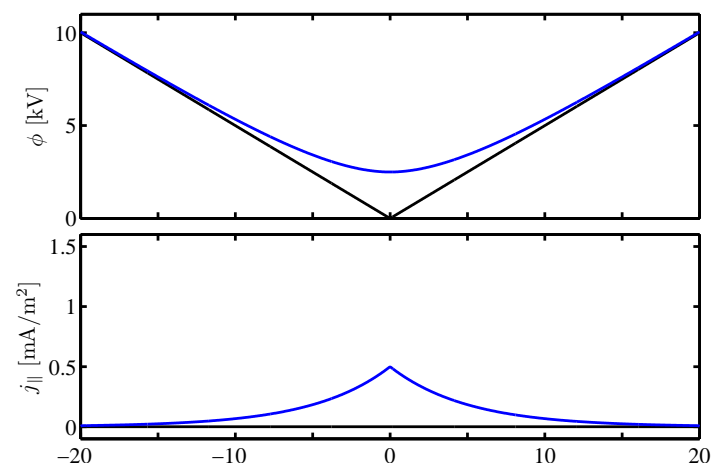

(d)

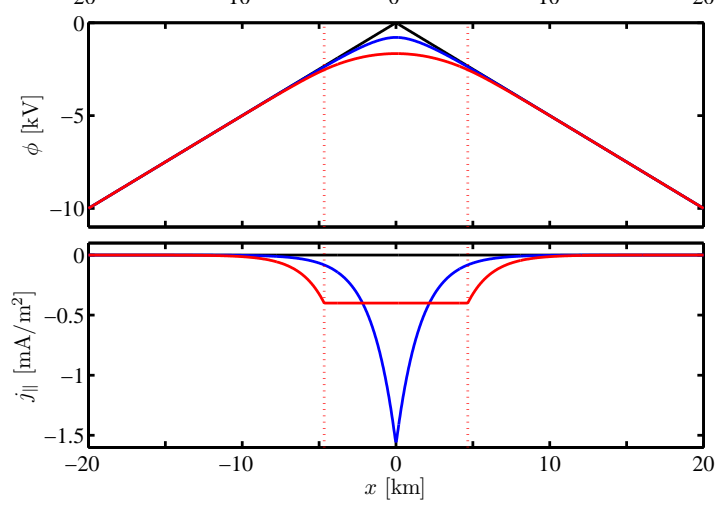

Fig. 3. Classification of solutions for converging/diverging electric fields; see also Table 1. For each class a pair of plots is given, showing the magnetospheric and ionospheric electric potential $\hat{\phi}$ (black) and $\phi$ (blue or red) as well as the field-aligned current $j_{\|}$(blue or red). A constant conductivity $\Sigma_{\mathrm{P}}=5 \mathrm{~S}$ was adopted. Both strong and weak electric fields, $|\epsilon|=100 \mathrm{mV} / \mathrm{m}$ and $500 \mathrm{mV} / \mathrm{m}$, are considered. Linear current-voltage relations are used, with $K_{-}=10 K_{+}$for corresponding converging/diverging field cases. The current and potential scales are the same for all panels. (a) A weak converging field, with $K_{+}=0.008 \mathrm{~mA} / \mathrm{kV} \mathrm{m}^{2}$, corresponds to a characteristic length $\lambda=25 \mathrm{~km}$ and a maximum parallel potential difference $\Delta \phi_{\max }=2.5 \mathrm{kV}$. (b) A weak diverging field, with $K_{-}=0.08 \mathrm{~mA} / \mathrm{kV} \mathrm{m}{ }^{2}$, produces a smaller $\Delta \phi_{\max }=0.79 \mathrm{kV}$. (c) A strong converging field, with $K_{+}=0.2 \mathrm{~mA} / \mathrm{kV} \mathrm{m}^{2}$, leads to $\lambda=5 \mathrm{~km}$ and the same $\Delta \phi_{\max }$ as in the first case. (d) A strong diverging field, with $K_{-}=2 \mathrm{~mA} / \mathrm{kV} \mathrm{m}^{2}$, gives the same $\Delta \phi_{\max }$ as in the second case, but with a larger current density peak (blue); with a return current limit the peak becomes a plateau, the layer is wider, and $\Delta \phi_{\max }=1.7 \mathrm{kV}$ is larger $\left(\mathrm{red}, j_{-}^{*}=-0.4 \mathrm{~mA} / \mathrm{m}^{2}\right)$.

different speeds $\pm \boldsymbol{v}$ on either side of their field-aligned interface produce a magnetospheric electric potential of the form $\hat{\phi}(x)=\epsilon|x|$,

where $\epsilon=-|\boldsymbol{v} \times \boldsymbol{B}|$ is the electric field strength. Such a potential is often referred to as a single- $\mathrm{V}$ potential (see also Lyons, 1980). It results from converging electric fields when $\epsilon>0$ and from diverging fields when $\epsilon<0$. For the linear current-voltage relation (Eq. 7) and for constant height-integrated conductivity, current conservation (Eq. 3) becomes

$\frac{\mathrm{d}^{2} \phi}{\mathrm{d} x^{2}}=\frac{K}{\Sigma_{\mathrm{P}}}(\phi(x)-\epsilon|x|)$,

with $K=K_{+}$or $K_{-}$; the boundary conditions

$\frac{\mathrm{d} \phi}{\mathrm{d} x}( \pm \infty)= \pm \epsilon, \quad \frac{\mathrm{d} \phi}{\mathrm{d} x}(0)=0$

are imposed. The nature of the problem is such that either $\Delta \phi>0$ everywhere for converging fields, corresponding to upward field-aligned currents and $K=K_{+}$, or $\Delta \phi<0$ everywhere for diverging fields, associated with downward fieldaligned currents and $K=K_{-}$. The ionospheric potential and field-aligned current are given by

$$
\begin{aligned}
& \phi(x)=\epsilon|x|+\epsilon \lambda \mathrm{e}^{-|x| / \lambda}, \\
& j_{\|}(x)=K \epsilon \lambda \mathrm{e}^{-|x| / \lambda}
\end{aligned}
$$

where $\lambda=\sqrt{\Sigma_{\mathrm{P}} / K}$ is an intrinsic length scale. The fieldaligned current densities (and also the height-integrated Pedersen current) scale linearly with the magnetospheric electric field strength $\epsilon$. The peak field-aligned potential difference $\Delta \phi_{\max }=\epsilon \lambda$ increases with $\lambda$ for a given magnetospheric configuration (given $\epsilon$ ): A high and uniform heightintegrated conductivity (large $\lambda$ ) does not support smallscale structures, so that the ionospheric potential must be smooth. A large Knight constant, however, does support smaller scales (small $\lambda$ ) since it implies larger $j_{\|}$and hence larger gradients of $\phi$. The peak field-aligned current, $j_{\| \max }=$ 
$\epsilon K \lambda=\epsilon \sqrt{K \Sigma_{\mathrm{P}}}$, grows with both the Knight constant and the conductivity.

Figure 3 shows the solutions for different values of $\epsilon$ and $K_{ \pm}$. All examples use a constant conductivity $\Sigma_{\mathrm{P}}=$ $5 \mathrm{~S}$. Figures $3 \mathrm{a}$ and $3 \mathrm{~b}$ correspond to a weak magnetospheric electric field $\epsilon= \pm 100 \mathrm{mV} / \mathrm{m}$. Note that $\epsilon$ is the magnetospheric field mapped to the ionosphere; the field measured in the magnetosphere would be lower. The magnetospheric electric field is stronger in Figs. $3 \mathrm{c}$ and $3 \mathrm{~d}$, $\epsilon=500 \mathrm{mV} / \mathrm{m}$. The Knight constants are chosen so as to obtain length scales of $\lambda=25 \mathrm{~km}$ and $\lambda=5 \mathrm{~km}$ for the weak and strong converging field cases, respectively. For Figs. 3a and $3 \mathrm{c}, K_{+}=0.008 \mathrm{~mA} / \mathrm{kV} \mathrm{m}^{2}$ and $0.2 \mathrm{~mA} / \mathrm{kV} \mathrm{m}^{2}$, respectively. For Figs. $3 \mathrm{~b}$ and $3 \mathrm{~d}$, values $K_{-}=0.08 \mathrm{~mA} / \mathrm{kV} \mathrm{m}^{2}$ and $2 \mathrm{~mA} / \mathrm{kV} \mathrm{m}^{2}$ were chosen so that $K_{-}>K_{+}$. This leads to smaller length scales and a lower peak field-aligned potential difference for the diverging field cases, as $\phi$ follows $\hat{\phi}$ quite closely, i.e., to strong localized downward currents.

The strong currents in narrow return current regions due to a large $K_{-}$might provoke the current limitation effect discussed earlier (Eq. 15). As long as the peak current $j_{\| \max }=\left|j_{\|}(0)\right|$ at the centre remains below the critical value, $j_{\| \max }<\left|j^{*}\right|$, (or, equivalently, $\Delta \phi_{\max }=\Delta \phi(0)<\Delta \phi^{*}$ ) the current is nowhere limited and the description of Eq. (17) applies. From Eq. (19) it is clear that a transition to the current limitation regime occurs when $\epsilon=\epsilon^{*}=j^{*} / \sqrt{K \Sigma_{\mathrm{P}}}$ (when $\Delta \phi_{\max }=\Delta \phi^{*}$ ). When $\epsilon$ is small, current densities remain below the treshold, while for large $\epsilon$ strong and localized field-aligned potential differences develop that drive the current density to the limit. For larger $\epsilon>\epsilon^{*}, j_{\|}=\left|j^{*}\right|$ and $\Delta \phi=\Delta \phi^{*}$ near the center of the domain. The current continuity equation then is

$$
\frac{\mathrm{d}^{2} \phi}{\mathrm{d} x^{2}}= \begin{cases}\frac{j_{ \pm}^{*}}{\Sigma_{\mathrm{P}}}, & |x| \leq x^{*}, \\ \frac{K_{ \pm}}{\Sigma_{\mathrm{P}}}(\phi(x)-\epsilon|x|), & |x|>x^{*} .\end{cases}
$$

By requiring continuity for $\phi$ and $\mathrm{d} \phi / \mathrm{d} x$ at $x^{*}$, and by imposing the same boundary conditions as before, one finds $x^{*}=\lambda\left(\epsilon-\epsilon^{*}\right) / \epsilon^{*}$; the ionospheric potential is

$\phi(x)= \begin{cases}\frac{\epsilon^{*}}{2 \lambda} x^{2}+\epsilon^{*} \lambda\left(1-\frac{x^{* 2}}{2 \lambda^{2}}\right)+\epsilon x^{*}, & |x| \leq x^{*}, \\ \epsilon|x|+\lambda \epsilon^{*} \mathrm{e}^{-\frac{|x|-x^{*}}{\lambda},}, & |x|>x^{*},\end{cases}$

corresponding to a current density

$j_{\|}(x)= \begin{cases}j_{ \pm}^{*}, & |x| \leq x^{*}, \\ j_{ \pm}^{*} \mathrm{e}^{-\frac{|x|-x^{*}}{\lambda}}, & |x|>x^{*} .\end{cases}$

A typical solution for the case of a strong diverging field is given by the red curves in Fig. 3d, corresponding to a maximum current $j_{-}^{*}=-0.4 \mathrm{~mA} / \mathrm{m}^{2}$. The current is at the constant maximum level for $|x| \leq x^{*}$, and thus $\phi(x)$ has a parabolic behaviour there (first case in Eq. 21). The sharp current density spike that occurs without current limit has now been changed into a broader peak with a lower maximum current density. As a result, the field-aligned potential difference has increased considerably.
Bearing all these considerations in mind, Fig. 3 illustrates a number of generic properties of the auroral current circuit. The converging electric field in Fig. 3a can be regarded as driving a broad region of diffusive auroral emission, in which a moderate upward field-aligned current is carried by downgoing electrons; the precipitating electrons are accelerated by an important $\Delta \phi$ and produce auroral emission over a region of significant width. The diverging electric field and the typically larger $K_{-}$of Fig. 3b, however, do not give rise to strong field-aligned potential differences. Hence, the ionospheric potential is very similar to the magnetospheric one. This can serve as a model of the current circuit above the subauroral polarization stream (SAPS) or the more pronounced subauroral ion drift (SAID), where the strong ionospheric electric field produces an important ion drift motion in the ionosphere. The stronger converging electric field in Fig. 3c creates a narrow structure with a large $\Delta \phi$, producing localized intense precipitation typical of a discrete auroral arc. For a diverging field, as in Fig. 3d, a field-aligned potential difference develops only if there is a limit to the return current. This can be considered to be a model for black aurora, in which the role of the electric potential is reversed as compared to the normal discrete aurora. A thorough discussion of these different configurations and their relation to observations will be given in the conclusions section.

Consider now a current-voltage relation with zeropotential currents (Eq. 11). Current conservation requires

$\frac{\mathrm{d}^{2} \phi}{\mathrm{d} x^{2}}=\frac{K_{ \pm}}{\Sigma_{\mathrm{P}}}(\phi(x)-\epsilon|x|)+\frac{j_{0 \pm}}{\Sigma_{\mathrm{P}}}$.

It is straightforward to see that the solution now is

$$
\begin{aligned}
& \phi(x)=\epsilon\left(|x|+\lambda \mathrm{e}^{-|x| / \lambda}\right)+\Delta \phi_{\mathrm{b}} \\
& j_{\|}(x)=K_{ \pm} \epsilon \lambda \mathrm{e}^{-|x| / \lambda},
\end{aligned}
$$

that is, the same current profile as before (Eq. 19), but with a potential that is shifted by $\Delta \phi_{\mathrm{b}}$, so that $\Delta \phi \rightarrow 0$ asymptotically. A small bias potential therefore does not really have a big influence on the overall configuration; it is therefore ignored in the remainder of this paper.

\section{Imprint of magnetospheric plasma variations}

It has by now been fairly well established that a magnetospheric interface that is coupled to the ionosphere may produce auroral phenomena (e.g., Roth et al., 1993; De Keyser, 1999; Johansson et al., 2006; Echim et al., 2007, 2009). Such an interface often implies strong changes in the magnetospheric plasma properties and thus a change in Knight's constant. A simple model assumes that $K=K_{1}$ for $x<0$ and $K=K_{2}$ for $x \geq 0$. Current conservation is still expressed by Eq. (17), but with different $K$ on either side of the interface. Requiring continuity of $\phi$ at the interface, and imposing the boundary conditions $\mathrm{d} \phi / \mathrm{d} x( \pm \infty)= \pm \epsilon$ and $\phi(0)=\phi_{0}$, one finds 

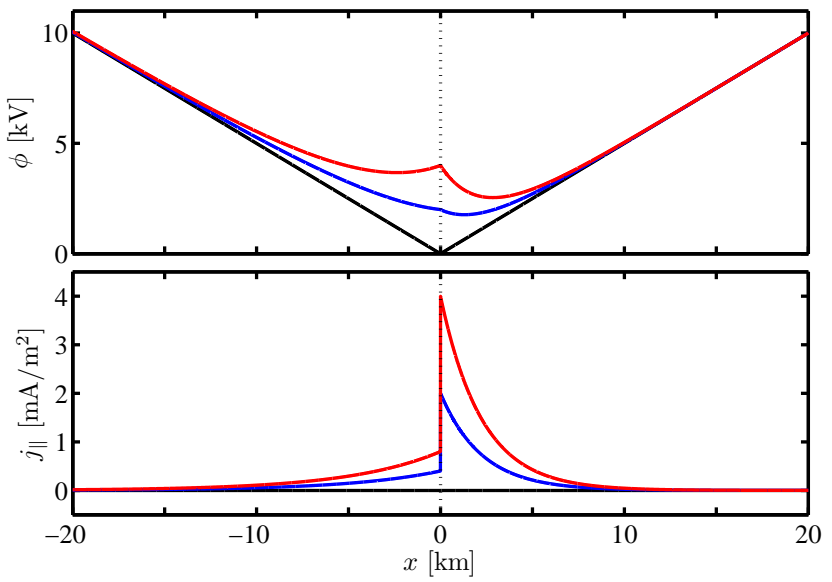

Fig. 4. Magnetospheric and ionospheric electric potential $\hat{\phi}$ (black) and $\phi$ (blue or red) and field-aligned current $j_{\|}$(blue or red) for a converging electric field $(\epsilon=500 \mathrm{mV} / \mathrm{m})$ and changing magnetospheric populations across the interface, expressed as a change in the Knight constant $\left(K_{1}=0.2 \mathrm{~mA} / \mathrm{kV} \mathrm{m}^{2}, K_{2}=1 \mathrm{~mA} / \mathrm{kV} \mathrm{m}^{2}\right)$. The two curves correspond to $\phi(0)=2 \mathrm{kV}$ (blue) and $\phi(0)=4 \mathrm{kV}$ (red). A constant conductivity $\Sigma_{\mathrm{P}}=5 \mathrm{~S}$ is used.

$$
\begin{aligned}
& \phi(x)= \begin{cases}-\epsilon x+\phi_{0} \mathrm{e}^{+x / \lambda_{1}}, & x<0, \\
+\epsilon x+\phi_{0} \mathrm{e}^{-x / \lambda_{2}}, & x \geq 0,\end{cases} \\
& j_{\|}(x)= \begin{cases}K_{1} \phi_{0} \mathrm{e}^{+x / \lambda_{1}}, & x<0, \\
K_{2} \phi_{0} \mathrm{e}^{-x / \lambda_{2}}, & x \geq 0,\end{cases}
\end{aligned}
$$

where $\lambda_{1,2}=\sqrt{\Sigma / K_{1,2}}$. Because of the sudden change in $K$ at the interface, the current is discontinuous there. Figure 4 illustrates the behaviour for $K_{1}=0.2 \mathrm{~mA} / \mathrm{kV} \mathrm{m}^{2}>$ $K_{2}=1 \mathrm{~mA} / \mathrm{kV} \mathrm{m}^{2}$, and for two different values of $\phi_{0}$. There is an apparent asymmetry, with shorter characteristic scales for $x \geq 0$ (largest $K$ ). This configuration can be associated with a magnetospheric interface between a less dense (on the left, small $K$ ) and a denser (on the right, large $K$ ) plasma of comparable temperature, e.g., inside the plasmasheet. A discrete arc is flanked by a broad region of weaker emission on the lower density side, as reflected by the $\Delta \phi$ asymmetry.

To properly understand the effects of plasma differences across the interface, however, a self-consistent model of the contact layer should be used, because the differences in density, temperature, and flow on either side of the interface all contribute to finite-gyroradius effects that produce smallscale structure in the plasma distribution and in the electric potential (e.g. De Keyser, 1999; Echim et al., 2007).

\section{Role of the magnetospheric electric potential}

Spatial variations in the magnetospheric potential profile $\hat{\phi}(x)$ leave their imprint on the ionospheric potential and on the resulting field-aligned currents. One example, already studied by Lyons (1981), is the double-V potential

$\hat{\phi}(x)= \begin{cases}\epsilon_{\text {in }}|x|, & |x| \leq L, \\ \epsilon_{\text {out }}(|x|-L)+\epsilon_{\text {in }} L, & |x|>L,\end{cases}$

which embeds an inner converging or diverging field region with length scale $L$ in an outer converging or diverging electric field environment. Such a magnetospheric potential arises when an inner shear flow region is embedded in the broader magnetospheric convection pattern, or it can be produced by the microphysics at the center of a shear flow layer (e.g., Echim et al., 2009). Consider again the constant conductivity case with boundary conditions $\mathrm{d} \phi( \pm \infty) / \mathrm{d} x=$ $\pm \epsilon_{\text {out }}$ and $\mathrm{d} \phi(0) / \mathrm{d} x=0$. Depending on $\epsilon_{\text {in }}$ and $\epsilon_{\text {out }}, \Delta \phi$ may change sign throughout the domain, creating an alternation of upward and downward field-aligned current regions. Figure 5 shows all possible classes of solutions, without (blue) or with a return current limit (various colours); it is assumed that the upward currents have no such limit or that the limit is so high that it is never reached. Each class is indicated with a code of the form $X Y s$, where $X$ is $C$ or $D$ indicating a converging or diverging outer electric field, $Y$ is $C, O$, or $D$, for strong converging inner field, a weak inner field of the same type as the outer field, or a diverging inner field, respectively; $s$ is,+- , or \pm , corresponding to a $\Delta \phi$ that is positive or negative everywhere, or that changes sign.

Figure 5, left column, illustrates the possibilities for converging outer fields. Class $C C+$, with a strong and localized converging electric field embedded in the weaker background field, gives rise to a structure with a width $2 L$, since the characteristic lengths $\lambda$ based on $\epsilon_{\text {in }}$ or $\epsilon_{\text {out }}$ are much larger. Such a narrow structure could model a discrete arc embedded in some broader diffusive auroral emission.

A different situation $C C \pm$ is obtained by considering different values of $K_{ \pm} ; \Delta \phi$ now changes sign. The upward current associated with the discrete arc is now flanked by return currents on either side (with or without return current limit). In this case, there is a zoo of length scales that may matter: $\lambda$ based on $\epsilon_{\text {in }}$ determines how spiky the upward current at the center is, $L$ is the imposed magnetospheric scale, $\lambda$ based on $\epsilon_{\text {out }}$ influences the thickness of the return current regions, ... Visually, this class would correspond to an arc that is clearly delimited from its surroundings (at least if the observer is looking along the magnetic field lines, to avoid line-of-sight effects).

The $\mathrm{CO}+$ class is similar to the single-V potential of Fig. $3 c$, but the structure is broader, its size being determined by both $L$ and the characteristic length $\lambda$ in the outer field.

When the inner field is diverging (classes $C D+$ and $C D \pm$ ), a double upward current structure is formed. Such configurations serve as a model for a pair of discrete arcs. The region between the arcs has either significantly less upward current (less or no precipitation) or a return current (possibly with return current limit), which would visually correspond a markedly darker region separating two bright 

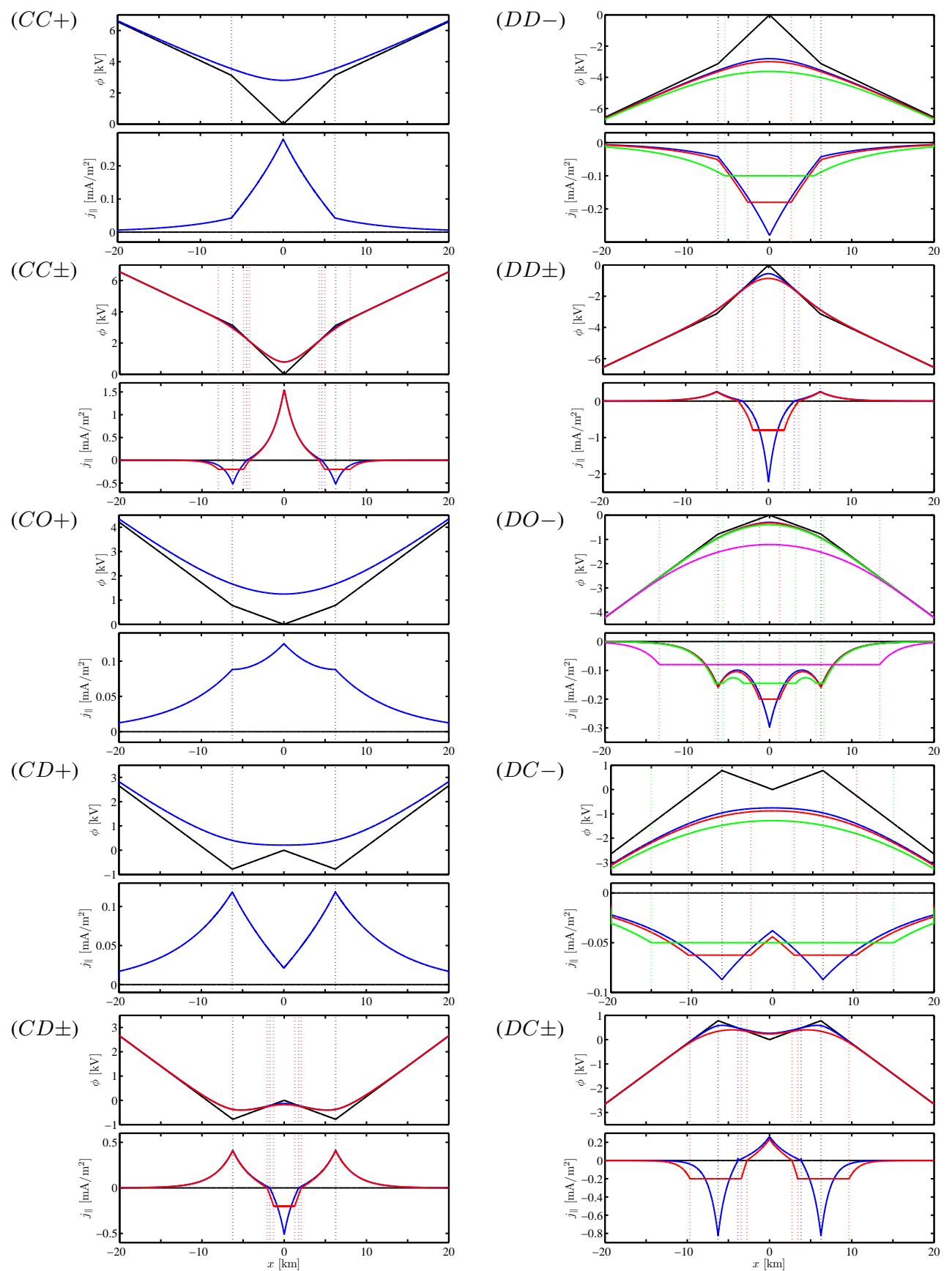

Fig. 5. Solution classes for nested electric fields. Each panel gives the magnetospheric and ionospheric potential $\hat{\phi}$ (black) and $\phi$ (various colors) and the field-aligned current $j_{\|}$(various colors), assuming $\Sigma_{\mathrm{P}}=5 \mathrm{~S}$. Left column, converging outer field $\epsilon_{\text {out }}=250 \mathrm{mV} / \mathrm{m}$ : $(\boldsymbol{C C}+)$ Strong converging inner field $\epsilon_{\text {in }}=500 \mathrm{mV} / \mathrm{m}, K_{+}=0.1 \mathrm{~mA} / \mathrm{kV} \mathrm{m}^{2}$. (CC \pm$)$ Same inner field, $K_{+}=2 \mathrm{~mA} / \mathrm{kV} \mathrm{m}^{2}, K_{-}=$ $4 \mathrm{~mA} / \mathrm{kV} \mathrm{m}^{2}$, without (blue, $\left.j_{-}^{*}=-\infty\right)$ or with return current limit (red, $\left.j_{-}^{*}=-0.2 \mathrm{~mA} / \mathrm{m}^{2}\right)$. $(\boldsymbol{C} \boldsymbol{O}+)$ Weak converging inner field $\epsilon_{\text {in }}=125 \mathrm{mV} / \mathrm{m}, K_{+}=0.1 \mathrm{~mA} / \mathrm{kV} \mathrm{m}^{2}$. (CD+) Diverging inner field $\epsilon_{\text {in }}=-125 \mathrm{mV} / \mathrm{m}, K_{+}=0.1 \mathrm{~mA} / \mathrm{kV} \mathrm{m}^{2}$. (CD $\left.\boldsymbol{C}\right)$ Same inner field, $K_{+}=1 \mathrm{~mA} / \mathrm{kV} \mathrm{m}^{2}, K_{-}=4 \mathrm{~mA} / \mathrm{kV} \mathrm{m}^{2}$, with $j_{-}^{*}=-\infty$ or $-0.2 \mathrm{~mA} / \mathrm{m}^{2}$ (blue, red). Right column, diverging outer field $\epsilon_{\text {out }}=-250 \mathrm{mV} / \mathrm{m}$ : ( $\boldsymbol{D} \boldsymbol{D}-$ ) Strong diverging inner field $\epsilon_{\mathrm{in}}=-500 \mathrm{mV} / \mathrm{m}, K_{-}=0.1 \mathrm{~mA} / \mathrm{kV} \mathrm{m}^{2}$, with $j_{-}^{*}=-\infty,-0.18$, or $-0.1 \mathrm{~mA} / \mathrm{m}^{2}$ (blue, red, green). ( $\boldsymbol{D} \boldsymbol{D} \pm$ ) Same inner field, $K_{+}=1 \mathrm{~mA} / \mathrm{kV} \mathrm{m}^{2}, K_{-}=4 \mathrm{~mA} / \mathrm{kV} \mathrm{m}^{2}$, with $j_{-}^{*}=-\infty$ or $-0.8 \mathrm{~mA} / \mathrm{m}^{2}$ (blue, red). (DOO-) Weak diverging inner field $\epsilon_{\text {in }}=-125 \mathrm{mV} / \mathrm{m}, K_{-}=1 \mathrm{~mA} / \mathrm{kV} \mathrm{m}^{2}$, with $j_{-}^{*}=-\infty,-0.2,-0.145$, or $-0.08 \mathrm{~mA} / \mathrm{m}^{2}$ (blue, red, green, magenta). (DC - ) Converging inner field $\epsilon_{\text {in }}=125 \mathrm{mV} / \mathrm{m}, K_{-}=0.05 \mathrm{~mA} / \mathrm{kV} \mathrm{m}^{2}$, with $j_{-}^{*}=-\infty,-0.0625$, or $-0.05 \mathrm{~mA} / \mathrm{m}^{2}$ (blue, red, green). (DC \pm ) Same inner field, $K_{+}=1 \mathrm{~mA} / \mathrm{kV} \mathrm{m}^{2}, K_{-}=4 \mathrm{~mA} / \mathrm{kV} \mathrm{m}^{2}$, with $j_{-}^{*}=-\infty$ or $-0.2 \mathrm{~mA} / \mathrm{m}^{2}$ (blue, red). 
auroral bands. This might be interpreted as black aurora, although that term is usually reserved for the case with a return current only (e.g. Marklund et al., 2001).

Figure 5, right column, shows the corresponding cases for a diverging outer field. Different alternative solutions illustrate how the return current limit leads to a broadening of the structure for the $D D-$ class with decreasing $\left|j_{-}^{*}\right|$. The various solution classes feature different combinations of upward and downward current regions.

The conclusion is that fairly simple local electric potential variations, embedded in their broader environment, can give rise to a wide variety of structures, including various length scales. A lower limit on these length scales must necessarily be the particle gyroradius scales. It is clear that the ionospheric signature of a particular magnetospheric structure strongly depends on its environment.

\section{Conductivity}

The finite ionospheric conductivity characterizes the load in the auroral current circuit. Within the context of the heightintegrated one-dimensional model described above, the discussion here is limited to the Pedersen conductivity. The Hall conductivity is ignored here, as it is typically smaller and as the field-aligned currents preferentially close through Pedersen currents (although this may not always be the case, see Robinson et al., 1987). It therefore makes sense, in a first approximation, to focus on the variations perpendicular to an essentially one-dimensional auroral structure.

The main effect of the ionospheric conductivity has already been illustrated in Sect. 4: the length scale of auroral structures $\lambda=\sqrt{\Sigma_{\mathrm{P}} / K}$ depends on $\Sigma_{\mathrm{P}}$. As photo-ionization by solar UV is responsible for much of the dayside conductivity, while that ionospheric electron content decays during the night, dayside auroral current systems tend to be broader, so that less discrete aurora or associated accelerated electron beams are observed during the day (Newell et al., 1996; Liou et al., 1997; Shue et al., 2001; Hamrin et al., 2005). An additional complication is, at least for auroral phenomena on closed field lines, that the magnetospheric generator drives two current circuits, one in either hemisphere. When the ionospheric conductivities are different, for instance, when one footpoint is sunlit and the other in darkness, the two conjugate current circuits should lead to interhemispheric asymmetries.

While the examples presented earlier assume a constant Pedersen conductivity throughout the auroral structure, local variations in the conductivity are also possible. The effects of such local variations are examined below.

\subsection{Spatially varying conductivities}

A first way to model the effects of local conductivity variations on the auroral circuit is to prescribe a spatial depen- dence $\Sigma_{\mathrm{P}}(x)$. Let the conductivity $\Sigma_{\text {Pin }}$ in an inner region $(|x| \leq P)$ be enhanced with respect to the conductivity $\Sigma_{\text {Pout }}$ in the environment. Such an enhancement is expected because precipitation produces additional free charges in the ionosphere. Given continuity of $\phi$ and $\mathrm{d} \phi / \mathrm{d} x$ at $x= \pm P$ and the boundary conditions $\mathrm{d} \phi( \pm \infty) / \mathrm{d} x= \pm \epsilon$ and $\mathrm{d} \phi(0) / \mathrm{d} x=$ 0 , the ionospheric potential is

$$
\phi(x)=\left\{\begin{aligned}
\epsilon|x|-\frac{\epsilon \lambda \gamma(\gamma-1)}{(\gamma+1) \mathrm{e}^{2} p / \gamma+(\gamma-1)} \mathrm{e}^{+|x| / \gamma \lambda} & \\
-\frac{\epsilon \lambda \gamma\left(\gamma+1 \mathrm{e}^{2} p / \gamma\right.}{(\gamma+1) \mathrm{e}^{2} p(\gamma+(\gamma-1)} \mathrm{e}^{-|x| / \gamma \lambda}, & |x| \leq P, \\
\epsilon|x|+\frac{2 \epsilon \lambda \gamma \mathrm{e} \frac{\gamma+1}{\gamma} p}{(\gamma+1) \mathrm{e}^{2} p / \gamma+(\gamma-1)} \mathrm{e}^{-|x| / \lambda}, & |x|>P,
\end{aligned}\right.
$$

where $\lambda$ refers to the length scale in the outer region, $p=$ $P / \lambda$ is the normalized width of the enhanced conductivity zone, and $\gamma^{2}=\Sigma_{\text {Pin }} / \Sigma_{\text {Pout }}$ denotes the ratio of the inner and outer conductivities. One can immediately see that this corresponds to Eq. (18) for $\Sigma_{\text {Pin }} \rightarrow \Sigma_{\text {Pout }}(\gamma \rightarrow 1)$, as well as for $p \rightarrow 0$. The solution is depicted in Fig. 6 . The blue curve gives the constant conductivity solution for reference, while the red curve depicts a typical solution for enhanced conductivity at the center. Enhanced conductivity implies a larger length scale in the inner region $(\gamma \lambda)$, so that the ionospheric potential does not vary much there. The maximum accelerating potential $\Delta \phi_{\max }^{\gamma}$ is modified with respect to its constant conductivity value $\Delta \phi_{\max }^{\gamma=1}=\epsilon \lambda$ by a factor

$F=\frac{\Delta \phi_{\max }^{\gamma}}{\Delta \phi_{\max }^{\gamma=1}}=\gamma \frac{(\gamma+1) \mathrm{e}^{2 p / \gamma}-(\gamma-1)}{(\gamma+1) \mathrm{e}^{2 p / \gamma}+(\gamma-1)}$

which increases monotonically with $\gamma$, but approaches $F=$ $1+p$ as $\gamma \rightarrow+\infty$, i.e., $\Sigma_{\text {Pin }} \gg \Sigma_{\text {Pout }}$. Indeed, for large $\gamma$, the ionospheric potential in the inner region becomes essentially constant, so that there must be a finite maximum factor by which the potential difference at the center is enhanced, and this factor must necessarily grow with $p$. A general conclusion that can be drawn from this example is that the fieldaligned potential difference increases with the conductivity at the center, but only to a certain extent. The field-aligned currents are more intense as well.

Equation (29) also applies to the case of reduced conductivity at the center. The limit for $\Sigma_{\text {Pin }} \ll \Sigma_{\text {Pout }}$ or $\gamma \rightarrow 0$ is $F=\gamma$, i.e., $\Delta \phi_{\max }^{\gamma}=\epsilon \gamma \lambda$, where $\gamma \lambda$ is the scale length in the inner region: The problem reduces to the case of a single- $\mathrm{V}$ profile with the inner region conductivity, while the outer region does not matter anymore.

\subsection{Conductivity and parallel potential difference}

Local conductivity changes tend to depend on the auroral phenomena themselves, e.g., on the precipitation, so that $\Sigma_{\mathrm{P}}(x, \Delta \phi(x))$ is a better description. This introduces, however, another form of nonlinearity in the current continuity equation, besides the possible nonlinearity of the currentvoltage relation. 

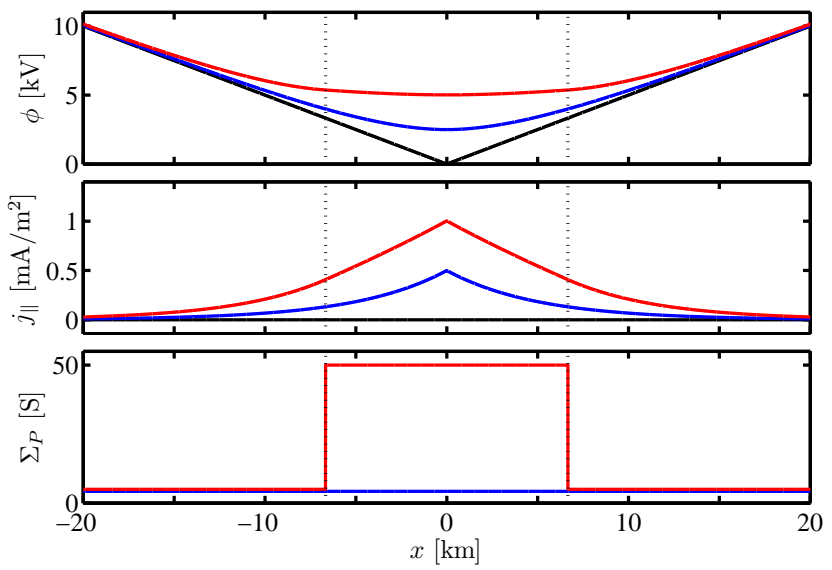

Fig. 6. Magnetospheric and ionospheric electric potential $\hat{\phi}$ (black) and $\phi$ (blue or red), field-aligned current $j_{\|}$(blue or red), and conductivity $\Sigma_{\mathrm{P}}$ (blue or red) for a converging electric field ( $\epsilon=$ $500 \mathrm{mV} / \mathrm{m}, K_{+}=0.2 \mathrm{~mA} / \mathrm{kV} \mathrm{m}^{2}$ ). The curves correspond to constant conductivity (blue, $\Sigma_{\mathrm{P}}=5 \mathrm{~S}$ ) or enhanced conductivity in a central region (red, $\Sigma_{\text {Pin }}=50 \mathrm{~S}, \Sigma_{\text {Pout }}=5 \mathrm{~S}$ ).

When $\Delta \phi>0$, precipitating magnetospheric electrons produce additional free charge carriers in the ionosphere. The conductivity depends on the energy flux associated with this precipitation, as this determines the production rate of free electrons, and therefore the Pedersen conductivity depends on $\Delta \phi$ (see, e.g., Harel et al., 1981; Lyons, 1981; Echim et al., 2008). When $\Delta \phi<0$, electrons may be removed from the ionosphere to a certain extent, lowering the conductivity. In both cases ionospheric winds convecting charge carriers into/out of the arc, diffusion, and photoionization (on the day side) affect the net conductivity.

Introducing the dependence of the conductivity on the field-aligned potential difference into the current continuity condition (Eq. 3) leads to

$\Sigma_{\mathrm{P}} \frac{\mathrm{d}^{2} \phi}{\mathrm{d} x^{2}}+\left[\frac{\partial \Sigma_{\mathrm{P}}}{\partial x}+\frac{\partial \Sigma_{\mathrm{P}}}{\partial \Delta \phi}\left(\frac{\mathrm{d} \phi}{\mathrm{d} x}-\frac{\mathrm{d} \hat{\phi}}{\mathrm{d} x}\right)\right] \frac{\mathrm{d} \phi}{\mathrm{d} x}=j_{\|}$,

which is a nonlinear ordinary differential equation. Consider, for instance, a linear relation between $\Sigma_{\mathrm{P}}$ and $\Delta \phi$ of the form

$\Sigma_{\mathrm{P}}=\Sigma_{0}+\delta \Sigma \Delta \phi$,

with $\delta \Sigma$ rather small. This is only a model choice aimed at obtaining an analytical expression for the solution, rather than the result of a linearization procedure. Inserting such a variable $\Sigma_{\mathrm{P}}$ into Eq. (30), and focusing on the case of converging electric fields and a linear current-voltage relation, one obtains (for $x>0$ )

$\left[1+\tau^{2}(\phi-\epsilon x)\right] \frac{\mathrm{d}^{2} \phi}{\mathrm{d} x^{2}}+\tau^{2}\left(\frac{\mathrm{d} \phi}{\mathrm{d} x}-\epsilon\right) \frac{\mathrm{d} \phi}{\mathrm{d} x}=\sigma^{2}(\phi-\epsilon x)$,

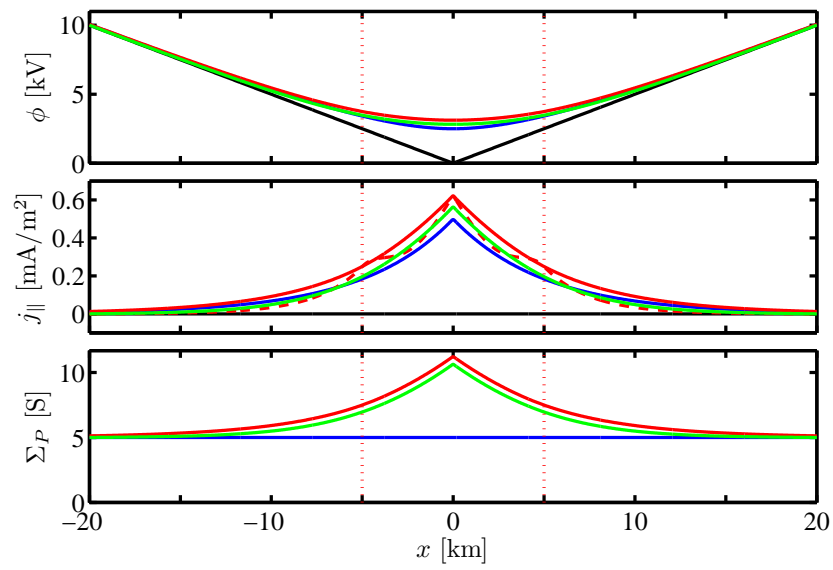

Fig. 7. Magnetospheric and ionospheric electric potential $\hat{\phi}$ (black) and $\phi$ (blue, red, green), field-aligned current $j_{\|}$(blue, red, green), and conductivity $\Sigma_{\mathrm{P}}$ (blue, red, green) for a converging electric field $\left(\epsilon=500 \mathrm{mV} / \mathrm{m}, K_{+}=0.2 \mathrm{~mA} / \mathrm{kV} \mathrm{m}^{2}\right)$. The curves correspond to constant conductivity $\Sigma_{\mathrm{P}}=\Sigma_{0}=5 \mathrm{~S}$ (blue) and a variable conductivity $\Sigma_{\mathrm{P}}=\Sigma_{0}+\delta \Sigma \Delta \phi$ with $\delta \Sigma=2 \mathrm{~S} / \mathrm{kV}$ (red and green). The solution is computed by an approximation (red, see text) or numerically (green). For the field-aligned currents, the solid red line shows $j_{\|}=K_{+} \Delta \phi$, while the dashed red line represents $j_{\|}=\mathrm{d}\left(\Sigma_{\mathrm{P}} \mathrm{d} \phi / \mathrm{d} x\right) / \mathrm{d} x$; the discrepancy between both indicates the quality of the approximation. This discrepancy is consistent with the numerical solution.

in which $\sigma^{2}=K / \Sigma_{0}$ and $\tau^{2}=\delta \Sigma / \Sigma_{0}$. This nonlinear equation cannot be solved analytically. An approximate solution can be obtained by subdividing the interval in inner and outer regions at points $\pm x^{*}$. For $|x|>x^{*}, \Sigma_{\mathrm{P}} \approx \Sigma_{0}$, allowing the solution with exponentially decaying potential difference as before, satisfying the boundary condition $\mathrm{d} \phi( \pm \infty) / \mathrm{d} x= \pm \epsilon$. For small $|x|$, the solution can be written as a polynomial of order $m>3$. Inserting this polynomial in the differential equation leads to a second-order recurrence relation for its coefficients. The boundary condition $\mathrm{d} \phi(0) / \mathrm{d} x=0$ is imposed, and one determines the coefficients of order $m-2, m-1$ and $m$ by requiring continuity of $\phi, \mathrm{d} \phi / \mathrm{d} x$, and $\mathrm{d}^{2} \phi / \mathrm{d} x^{2}$ at $x^{*}$. A typical result is shown in Fig. 7, for $\Sigma_{0}=5 \mathrm{~S}$ and $\delta \Sigma=2 \mathrm{~S} / \mathrm{kV}$, obtained with a 7th order polynomial. The quality of the approximation degrades as $\delta \Sigma$ becomes larger. This quality can be assessed by comparing $j_{\|}$computed from the current-voltage relation (solid red line) and from filling in the approximate $\phi$ in the left hand side of Eq. (30) (dashed red line), both of which are slightly different. The figure also gives the numerical solution (green). The difference between the two ways of computing the currents in the approximate solution is of the same order as their difference from the numerical solution.

Figure 7 illustrates how the conductivity reaches a peak in the region of strong upward currents (due to precipitating magnetospheric electrons), thereby further enhancing $\Delta \phi$ 


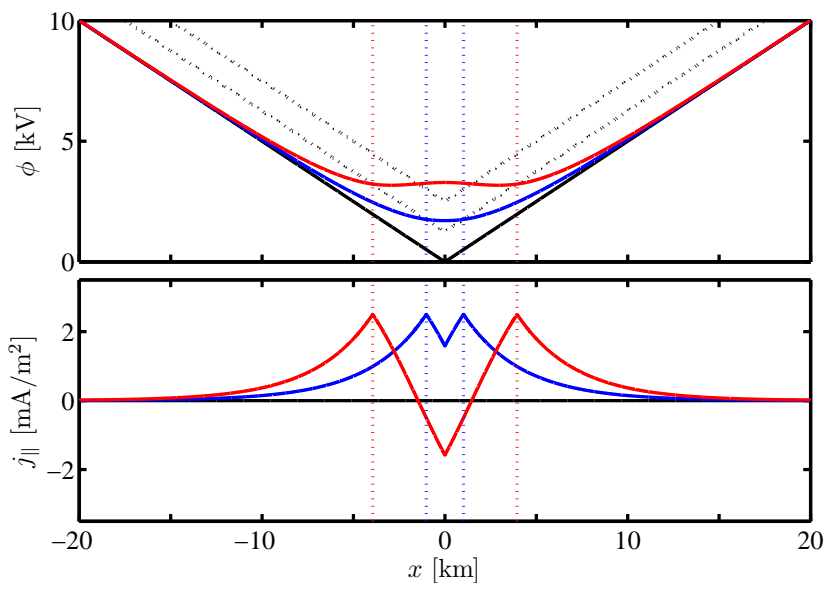

Fig. 8. Magnetospheric and ionospheric electric potential $\hat{\phi}$ (black) and $\phi$ (blue and red) and field-aligned current $j_{\|}$(blue and red) for a converging electric field $(\epsilon=500 \mathrm{mV} / \mathrm{m})$, a conductivity of $\Sigma_{\mathrm{P}}=$ $20 \mathrm{~S}$, and a nonmonotonic current-voltage relation $j_{\|}=K_{+} \Delta \phi$ for $\Delta \phi<\Delta \phi^{*}$ and $j_{\|}=2 K_{+} \Delta \phi^{*}-K_{+} \Delta \phi$ for higher parallel potential drop. Dotted black lines indicate $\Delta \phi=\Delta \phi^{*}$ (where the current is maximum) and $2 \Delta \phi^{*}$ (where the current is zero), with $K_{+}=2 \mathrm{~mA} / \mathrm{kV} \mathrm{m}^{2}$ and $\Delta \phi^{*}=1.25 \mathrm{kV}$. The two curves correspond to two different solutions for the same boundary conditions.

and $j_{\|}$. This type of ionospheric feedback on the auroral current system has been addressed in the past (e.g., Southwood and Wolf, 1978; Newell et al., 1996). It has been studied in detail in the context of quasi-static models by Echim et al. (2008). As a consequence, the peak current density increases and the width of the structure is reduced, although that effect becomes apparent only for more dramatic conductivity enhancements. A similar feedback exists for the return current regions, where the conductivity is reduced by an evacuation of electrons from the ionosphere.

\section{Existence of a unique solution}

In the case of constant conductivity and a linear currentvoltage relation, and for a magnetospheric potential profile $\hat{\phi}$ that is piecewise linear in different regions of space, one can consider the solution in each region: Since $\mathrm{d}^{2} \hat{\phi} / \mathrm{d} x^{2}=0$, $\mathrm{d}^{2} \phi / \mathrm{d} x^{2}=\mathrm{d}^{2} \Delta \phi / \mathrm{d} x^{2}$ so that the current conservation equation can be expressed as

$$
\frac{\mathrm{d}^{2}}{\mathrm{~d} x^{2}} \Delta \phi=\frac{K_{ \pm}}{\Sigma_{\mathrm{P}}} \Delta \phi
$$

which has either sine- or exponential-type solutions, depending on the sign of the Knight constant. One can then try to match the solutions in the different regions. When the overall current-voltage relation is not linear (e.g., it could be only piecewise linear), and in particular for nonmonotonic rela- tionships where $\partial j_{\|} / \partial \Delta \phi<0$, uniqueness is no longer guaranteed. As an example, consider

$$
j_{\|}= \begin{cases}K_{+} \Delta \phi, & \Delta \phi \leq \Delta \phi^{*}, \\ 2 K_{+} \Delta \phi^{*}-K_{+} \Delta \phi, & \Delta \phi^{*}<\Delta \phi,\end{cases}
$$

with $K_{+}>0$, in which the current first grows with $\Delta \phi$, then decreases starting from $\Delta \phi^{*}$, and eventually becomes negative at $2 \Delta \phi^{*}$. Figure 8 shows two solutions for a converging electric field configuration. For the parameter values used in this example, there is no solution with $\Delta \phi<\Delta \phi^{*}$ everywhere. Writing down Eq. (17) for the regions where $\Delta \phi$ is larger or smaller than $\Delta \phi^{*}$, corresponding to both cases in the current-voltage relation, imposing the boundary conditions $\mathrm{d} \phi(0) / \mathrm{d} x=0$ and $\mathrm{d} \phi( \pm \infty) / \mathrm{d} x= \pm \epsilon$, and imposing continuity of $\phi$ and $\mathrm{d} \phi / \mathrm{d} x$ at the point $\xi$ where $\Delta \phi=\Delta \phi^{*}$, leads to a nonlinear equation for $\xi$. This equation may have zero, one, or more solutions; in the present example there are (at least) two, as depicted in the figure. The first solution (blue) has $j_{\|}>0$ everywhere; the second solution (red) has $j_{\|}<0$ at the center so that $\mathrm{d}^{2} \phi / \mathrm{d} x^{2}$ changes sign. Note that the parameters have been chosen to produce a clear example, rather than being particularly physically relevant.

One may ask whether this type of current-voltage relation is not an abnormal one. Indeed, if property (4) holds for each population $s$, then the overall current-voltage relation must satisfy that property too since

$$
\frac{\partial j_{\|}}{\partial \Delta \phi}=\sum_{s} \frac{\partial j_{\| s}}{\partial \Delta \phi}>0 \text {. }
$$

As discussed in Sect. 3, such a monotonic behaviour is expected to be characteristic of the auroral current system, certainly for larger $|\Delta \phi|$.

The issue of solution existence and uniqueness becomes less obvious when the conductivity depends on the solution. This form of nonlinearity is harder to deal with. One would expect that the existence and uniqueness of a solution are guaranteed if the conductivity does not depend too sensitively on the solution, since this is close to the constant conductivity case. In reality, however, the conductivity can be quite sensitive. It appears that solutions often exist (e.g., the solutions presented by Lyons, 1980; Echim et al., 2008), but it is difficult to show that these are unique.

\section{Numerical solution of the current continuity equation}

The numerical solution of the current continuity equation is affected by the nonlinear nature of $j_{\|}(x, \Delta \phi)$ and of $\Sigma_{\mathrm{P}}(x, \Delta \phi)$. The numerical scheme outlined below treats both sources of nonlinearity differently.

Starting with an initial solution $\phi^{[0]}$ and conductivity profile $\Sigma_{\mathrm{P}}^{[0]}(x)=\Sigma_{\mathrm{P}}\left(x, \phi^{[0]}-\hat{\phi}\right)$, an improved solution $\phi^{[l]}$ is computed in an outer iteration for $l=1,2, \ldots$ and the conductivity profile $\Sigma_{\mathrm{P}}^{[l]}(x)=\Sigma_{\mathrm{P}}\left(x, \phi^{[l]}-\hat{\phi}\right)$ is updated accordingly, until the conductivity profile does not significantly 
change any more. The solution to the problem is then found. A damped iteration scheme can be used to avoid problems with the nonlinearity.

In each step, a solution has to be computed for a problem in which $\Sigma_{\mathrm{P}}^{[l]}(x)$ is given, i.e., where $\partial \Sigma_{\mathrm{P}} / \partial \Delta \phi=0$, so that only the nonlinearity due to the current-voltage relation has to be dealt with. To that end, a Newton method can be used, which requires an inner iteration. Assume that an approximate solution $\phi^{(k)}(x)$ to the current continuity equation

$$
\frac{\mathrm{d}}{\mathrm{d} x}\left(\Sigma_{\mathrm{P}}(x) \frac{\mathrm{d} \phi}{\mathrm{d} x}\right)=j(x, \Delta \phi)
$$

is known. It can be improved by doing an update

$\phi^{(k+1)}(x)=\phi^{(k)}(x)+\delta \phi^{(k)}(x)$,

where correction $\delta \phi^{(k)}(x)$ is found from linearizing Eq. (34):

$$
\begin{gathered}
\Sigma_{\mathrm{P}}(x) \frac{\mathrm{d}^{2} \delta \phi^{(k)}}{\mathrm{d} x^{2}}+\frac{\mathrm{d} \Sigma_{\mathrm{P}}(x)}{\mathrm{d} x} \frac{\mathrm{d} \delta \phi^{(k)}}{\mathrm{d} x}-\frac{\partial j_{\|}\left(x, \phi^{(k)}-\hat{\phi}\right)}{\partial \Delta \phi} \delta \phi^{(k)} \\
\approx j\left(x, \phi^{(k)}-\hat{\phi}\right)-\Sigma_{\mathrm{P}}(x) \frac{\mathrm{d}^{2} \phi^{(k)}}{\mathrm{d} x^{2}}-\frac{\mathrm{d} \Sigma_{\mathrm{P}}(x)}{\mathrm{d} x} \frac{\mathrm{d} \phi^{(k)}}{\mathrm{d} x} ;
\end{gathered}
$$

the approximation is exact if $j_{\|}$depends linearly on $\Delta \phi$. A straightforward second-order accurate discretization in a set of equidistant points $x_{i}$ with spacing $h$ is

$$
\begin{aligned}
\left(\Sigma_{\mathrm{P}, i}\right. & \left.+\frac{\Sigma_{\mathrm{P}, i+1}-\Sigma_{\mathrm{P}, i-1}}{4}\right) \delta \phi_{i+1}^{(k)} \\
& -\left(2 \Sigma_{\mathrm{P}, i}+h^{2} \frac{\partial j_{\|_{i}}}{\partial \Delta \phi}\right) \delta \phi_{i}^{(k)} \\
& +\left(\Sigma_{\mathrm{P}, i}-\frac{\Sigma_{\mathrm{P}, i+1}-\Sigma_{\mathrm{P}, i-1}}{4}\right) \delta \phi_{i-1}^{(k)} \\
= & h^{2} j_{\|_{i}}-\Sigma_{\mathrm{P}, i}\left(\phi_{i+1}^{(k)}-2 \phi_{i}^{(k)}+\phi_{i-1}^{(k)}\right) \\
& -\frac{\Sigma_{\mathrm{P}, i+1}-\Sigma_{\mathrm{P}, i-1}}{2} \frac{\phi_{i+1}^{(k)}-\phi_{i-1}^{(k)}}{2},
\end{aligned}
$$

which (together with the boundary conditions) forms a linear system for the discretized correction. As the discretization is refined $(h \rightarrow 0)$, the coefficient matrix becomes more diagonal dominant, so that a unique solution exists in the neighborhood of the initial guess: Starting this Newton technique from $\phi^{(0)}=\phi^{[l]}$, successive improvements are obtained until $\phi^{(k)}$ converges. A damped Newton update with damping factor $\omega \in[0,1)$ is then obtained by taking

$\phi^{[l+1]}=\omega \phi^{[l]}+(1-\omega) \phi^{(k)}$.

When $\omega=0$ (no damping), the improved solution is taken as the starting point for the next outer iteration step, while for $\omega>0$ a more conservative choice is made in the sense that the solution of the previous outer iteration step is not completely abandoned; this is a well-known technique to enlarge the domain of convergence of the Newton iteration.

The proposed nested iteration method is quite efficient, especially if one accounts for the fact that the inner iteration has to be solved only to an accuracy of the order of the current precision of the outer iteration. In addition, an intelligent use of damping with an adaptive choice of $\omega$ offers a good combination between robustness and computational efficiency. The numerical solution in Fig. 7 (green) has been computed with this technique.

This semi-Newton method (Newton for the $j_{\|}$nonlinearity, a damped update for the $\Sigma_{\mathrm{P}}$ nonlinearity) requires the computation of $\partial j_{\|} / \partial \Delta \phi$ (which is usually available), but it avoids the need for an explicit expression for $\partial \Sigma_{\mathrm{P}} / \partial \Delta \phi$. That might be useful if the ionospheric conductivity itself is computed from a simulation.

\section{Conclusions}

Auroral phenomena are manifestations of multi-scale dynamics in the coupled magnetosphere-ionosphere system. This coupling can be described by an auroral electric current circuit, which is intimately linked to the transport of particles and energy in the system and which therefore has a decisive influence on the main properties of auroral features. In this paper, we have described the current continuity equation and its main properties, in terms of the properties of the generator electrostatic potential, of the current-voltage relation describing the magnetosphere-ionosphere connection, and of the load. We have examined the role of the different physical elements in the current circuit by means of model problems.

In Sect. 4 we have shown how the interplay between properties of the current-voltage relation (Knight constant, current limit) and of the magnetospheric potential (weak or strong converging or diverging fields) is capable, even in the context of a very simple model, to explain the major properties of diffuse aurora, discrete auroral arcs, subauroral ion drift, and black aurora. An overview of the conclusions is presented in Table 1. This table classifies auroral phenomena based on the properties of the associated current circuit. This classification is robust, in the sense that typical variations in ionospheric conductivity or plasma populations do not alter the results qualitatively. The fundamental assumptions are

1. that the Knight constant must be higher for the return current than for the upward current, and

2. that there is a relatively low limit to the return current.

As discussed in Sect. 3, both assumptions appear to be quite reasonable. We have shown that these assumptions lead to a classification of auroral phenomena based on the properties of the electrostatic current circuit (see Table 1), that matches a large number of observed features of the magnetosphereionosphere coupling.

1. For converging electric fields, the Knight constant and the ionospheric conductivity lead to field-aligned potential drops that can accelerate the precipitating magnetospheric electrons and upgoing ionospheric ions; this 
Table 1. Classification of auroral phenomena based on the properties of the current circuit for a simple converging/diverging electric field configuration. The underlying assumptions are that the return current is characterized by a higher Knight constant than the upward current, and that it is limited to a relatively low maximum value.

\begin{tabular}{ccccccc}
\hline magnetospheric electric field & $|\boldsymbol{E}|$ & $\Delta \phi$ sign & $|\Delta \phi|$ & $\Sigma_{\mathrm{P}}$ & ionospheric scale & ionospheric phenomenon \\
\hline converging & weak & + & modest & modest & medium-wide $(100-1000 \mathrm{~km})$ & diffuse aurora \\
converging & strong & + & large & large & narrow $(1-10 \mathrm{~km})$ & discrete aurora \\
diverging & weak & - & small & low & medium-wide $(100-1000 \mathrm{~km}$ & SAPS, SAID \\
diverging & strong & - & modest & low & narrow $(1-10 \mathrm{~km})$ & black aurora \\
\hline
\end{tabular}

will enhance the free electron content and the conductivity in the ionosphere. Such configurations may lead to diffuse aurora. The importance of these accelerating parallel electric fields has been recognized for a long time (e.g. Lyons, 1980; Feldstein and Galperin, 1985; Galperin and Feldshtein, 1989; Block and Fälthammar, 1990), although there still remain uncertainties such as to what altitudes these fields actually extend (Johansson et al., 2009).

2. Stronger converging fields lead to higher parallel potential differences, stronger upward field-aligned currents, even higher ionospheric conductivity, and accelerated upgoing ions, all typical of discrete auroral arcs (e.g. Lyons, 1981; Carlson et al., 1998; Vaivads et al., 2003; Figueiredo et al., 2005; Liléo et al., 2008; Echim et al., 2009). A statistical study by Johansson et al. (2007) points out that the scale sizes of intense electric field signatures, of the field-aligned currents, and of the density gradients observed above the auroral zone at 5$7 R_{\mathrm{E}}$ geocentric distance were compatible, supporting the overall picture of a magnetospheric interface associated with the arc structure, and determining its thickness. The association of magnetospheric interfaces with these strong electric fields has been demonstrated in various case studies (e.g. Vaivads et al., 2003; Johansson et al., 2006; Kullen et al., 2008; Liléo et al., 2008). Note that the electrostatic model presented here predicts that transverse ionospheric electric fields can exist on both sides of an arc, which must give rise to oppositely directed plasma convection along the arc (Kullen et al., 2008).

3. The large Knight constant in the return current region strongly suppresses field-aligned potential differences for diverging fields. The consequence is that in such cases the magnetospheric potential is simply mapped onto the ionosphere, boosting the perpendicular electric field strength by an order of magnitude. The absence of significant field-aligned potential differences and fieldaligned currents, despite the presence of very strong perpendicular electric fields, has been an intriguing property of subauroral ion drifts (Banks and Yasuhara, 1978; Marklund et al., 1995) but can be explained simply by a large return current Knight constant and the low conductivity. The main ionospheric effect is a plasma drift $\boldsymbol{v}_{\mathrm{d}}=\boldsymbol{E} \times \boldsymbol{B} / B^{2}$. Such drift events are called subauroral polarization streams (SAPS), or subauroral ion drift (SAID) when the drift becomes more localized and intense, in excess of $1 \mathrm{~km} / \mathrm{s}$ (Galperin et al., 1973; Smiddy et al., 1977; Spiro et al., 1979; Rich et al., 1980; Filippov et al., 1984; Anderson et al., 1993, 2001; PuhlQuinn et al., 2007). The ionospheric ion and electron temperature is enhanced, while the electron content and conductivity tend to be low (Galperin et al., 1986; Deminov and Shubin, 1988; Filippov et al., 1989; Anderson et al., 1991; Rodger et al., 1992; Ober et al., 1997; Figueiredo et al., 2004; Prölss, 2006), so that less power is drawn from the generator. A range of diverging field strengths exists (Karlsson et al., 1998); very strong fields and the associated drifts might produce stable auroral red arcs as a consequence of the ion and electron heating due to ion-neutral collisions (Hoch and Lemaire, 1974; Foster et al., 1994; Moffett et al., 1998). SAPS and SAID have substantial effects on the plasmasphere and the ring current, and on the overall configuration of the inner magnetosphere (Foster et al., 1994; Ober et al., 1997; De Keyser, 1999; Goldstein et al., 2003, 2005; Gurgiolo et al., 2005; Foster et al., 2007; Voiculescu and Roth, 2008).

4. For even stronger diverging electric fields, significant field-aligned potential differences still can exist in narrow return current structures when there is a finite limit to the current, such as in black aurora, leading to upward acceleration of electrons (Marklund et al., 1994, 1995, 1997, 2001; Carlson et al., 1998). Most intense diverging electric field structures in the auroral zone have indeed been observationally associated with return currents (Johansson et al., 2005). Because of the low ionospheric conductivity, these structures tend to be very thin (1 km scale).

In the light of these findings, it is not surprising that lowaltitude satellite missions, such as Freja, found predominantly strong divergent electric fields (Marklund et al., 1995): Converging magnetospheric electric fields are efficiently smoothed through the existence of the field-aligned potential 
difference, while wide diverging electric field structures simply map down to the ionosphere (strengthened by the mapping factor) and narrow diverging fields do get smoothed by a field-aligned potential drop, but this potential drop appears to be at least partially below the low altitude satellite orbit as it must be able to extract electrons from the ionosphere (Vedin and Rönnmark, 2005).

Simple local electric potential variations, embedded in a broader environment, can create a diversity of ionospheric features at multiple length scales. The examples of Sect. 6 show that the scales can even be finer than the scales of the magnetospheric potential structures; the electron gyroradius would of course be the smallest possible scale. The quasi-static model presented here ascribes the wide variety of observed arc thicknesses in the large- to meso-scale range (Borovsky, 1993; Knudsen et al., 2001; Dahlgren et al., 2008) to gyroradius-dependent properties of the magnetospheric generator, to intrinsic length scales of the current system as determined by the field-aligned currents and the ionospheric conductivity, and combinations thereof. The solutions indicate how adjacent regions of upward, downward, and zero currents often co-exist, something that is commonly observed (Lühr et al., 1994). Clearly, the ionospheric signature of a local magnetospheric electrostatic structure depends strongly on the broader electrostatic configuration.

The magnetospheric electric fields discussed in the present paper require an electromotive force in the form of a magnetospheric generator (as in Lyons, 1980, 1981; Roth et al., 1993; De Keyser, 1999; Echim et al., 2007, 2008, 2009). First and foremost, converging and/or diverging electric fields may reflect convection. Since the magnetospheric convection is driven by the solar wind-magnetosphere interaction, the solar wind is the source of the energy dissipated in the ionosphere in auroral phenomena. Magnetospheric flow shears are expected, for instance, on closed field lines near the plasmasphere and near the edges of plasmaspheric plumes, especially when hot plasmasheet plasma is injected in the inner magnetosphere during a substorm (McIlwain, 1974; Newell and Meng, 1987; Baker and McPherron, 1990), and in the low latitude boundary layer where the antisunward flow of magnetosheath plasma interfaces with the magnetospheric plasma (Lundin and Evans, 1985; Feldstein et al., 2001; Echim et al., 2008), but also in the plasmasheet (Galperin and Feldshtein, 1989; Baumjohann et al., 1990; Angelopoulos et al., 1992; Chen et al., 2000; Figueiredo et al., 2005; Hamrin et al., 2006; Marghitu et al., 2006; Liléo et al., 2008; Johansson et al., 2009). A second type of electric fields are charge separation electric fields, possibly strengthened by the presence of shear flows, especially at interfaces between cold (plasmasphere/plasmatrough or lobe) and hot (plasmasheet) plasmas, as invoked for discrete arc and subauroral ion drift generators (Ejiri et al., 1980; Feldstein and Galperin, 1985; Yeh et al., 1991; Roth et al., 1993; Lemaire et al., 1998; De Keyser et al., 1998; De Keyser, 1999, 2000; Johansson et al., 2006; Echim et al., 2007); such fields are capable of creating fine scale structure. Charge separation fields are typically produced at an interface between plasmas with different temperatures or composition: Because their gyroradii are different, exact charge neutrality is impossible to achieve in the interface (Roth et al., 1996). The resulting electric field structures scale with the hot particle energy, and imprint the gyroradius scale lengths on the magnetospheric electric potential profile and thus on the aurora associated with it. The corresponding spatial scales match the $1-10 \mathrm{~km}$ width of meso-scale discrete arcs. The sense of the charge separation electric field is determined by the relative position of the hot and cold plasmas; this can explain, for instance, the predominantly westward ion drift in SAPS and SAID (De Keyser, 1999). Finally, inductive electric fields are short-lived and do not matter in a quasi-static regime.

An aspect that has not been addressed here is the modification of the magnetospheric generator as soon as the auroral current system is closed. The generator depicted in Fig. 1 is associated with a tangential discontinuity interface. But once a load is attached to the voltage generator, the fieldaligned currents flowing to and from the ionosphere tend to destroy the charge distribution in the interface. One aspect of this modification are, for instance, the upward accelerated ionospheric ion beams observed in precipitating electron regions or farther out in presumed generator regions such as the plasmasheet boundary layer, or, conversely, the upgoing electron beams in return current regions (Parks et al., 1997, 1998; Carlson et al., 1998; Chen et al., 2000; Echim et al., 2009). The loaded generator is not too much different from the unloaded one, however, if the structure is able to regenerate itself continuously. It can be verified (see Roth et al., 1993; De Keyser, 1999) that the particle losses can be replenished rather easily by a small normal flow toward the interface; as long as the replenishment is maintained, the structure is quasi-static. The generator in the loaded circuit then can no longer be a strict tangential discontinuity, as it drives a current $I_{G}$ across the field lines.

An important open issue is the question how to reconcile the electrostatic picture, which seems to agree pretty well with a host of observations, with the kinetic Alfvén wave description, which is also supported by observations. Of course, Alfvén waves must play a role in setting up an electrostatic configuration, since they communicate the magnetospheric fields to the ionosphere (e.g. Rönnmark and Hamrin, 2000). A promising description is that of aurora in terms of stationary inertial Alfvén waves (Knudsen, 2001). Waves can be provoked by a feedback instability that can structure auroral arcs (see, e.g. Atkinson, 1970; Sato, 1978; Lysak, 1986, 1991; Lysak and Song, 2002). Alfvén waves can mediate the parallel currents and electric fields on auroral field lines, including standing Alfvén waves in field line resonances (Lee et al., 2001; Prakash and Rankin, 2001). Counter-propagating particle beams in or above the acceleration region can excite various types of waves. Enhanced wave activity might also play an essential role in providing 
the diffusion or pitch-angle scattering that is needed for keeping the loss cone populated and regenerating the magnetospheric interface structure, thereby affecting the currentvoltage relation (e.g. Schriver, 1999; Swift, 2001).

This paper has not dealt with the impact of ionospheric dynamics on the auroral current system. Nevertheless, it is clear that the effects of ion-neutral collisions and neutral winds may be important. Ion drag and Joule and particle precipitation heating may set up a thermospheric buoyant circulation (Walterscheid et al., 1985). Lyons and Walterscheid (1986) have supplemented the current continuity equation with a one-dimensional neutral wind model and found that the neutral wind due to the ion drag does not affect the resulting arcs very much; however, in the presence of neutral crossarc winds the situation might be different (Walterscheid and Lyons, 1992). Neutral winds may, in fact, through ionneutral collisions, modify the magnetospheric electric field.

Acknowledgements. This work was supported by the Belgian Science Policy Office through Prodex/CLUSTER (contract 13127/98/NL/VJ(IC)) and the Belgian Solar-Terrestrial Centre of Excellence. The authors acknowledge fruitful discussions with M. Roth, R. Maggiolo, G. Marklund and M. Voiculescu concerning the role of field-aligned potential differences in auroral phenomena, and thank E. Rigo for his kind bibliographical assistance.

Topical Editor I. A. Daglis thanks R. Demajistre and another anonymous referee for their help in evaluating this paper.

\section{References}

Anderson, P. C., Hanson, W. B., and Heelis, R. A.: The ionospheric signatures of rapid subauroral ion drifts, J. Geophys. Res., 96, 5785-5792, 1991.

Anderson, P. C., Hanson, W. B., Heelis, R. A., Craven, J. D., N., B. D., and Frank, L. A.: A proposed production model of rapid subauroral ion drift and their relationship to substorm evolution, J. Geophys. Res., 98, 6069-6078, 1993.

Anderson, P. C., Carpenter, D. L., Tsuruda, K., Mukai, T., and Rich, F. J.: Multisatellite observations of rapid subauroral ion drifts (SAID), J. Geophys. Res., 106, 29585-29599, 2001.

Angelopoulos, V., Baumjohann, W., Kennel, C. F., Coroniti, F. V., Kivelson, M. G., Pellat, R., Walker, R. J., Lühr, H., and Paschmann, G.: Bursty bulk flows in the inner central plasma sheet, J. Geophys. Res., 97, 4027-4039, 1992.

Atkinson, G.: Auroral arcs: result of the interaction of a dynamic magnetosphere with the ionosphere, J. Geophys. Res., 75, 47464755, 1970.

Baker, D. N. and McPherron, R. L.: Extreme energetic particle decreases near geostationary orbit: A manifestation of current diversion within the inner plasma sheet, J. Geophys. Res., 95, 6591-6599, 1990.

Banks, P. M. and Yasuhara, F.: Electric fields and conductivity in the nighttime E-region: A new magnetosphere-ionosphereatmosphere coupling effect, Geophys. Res. Lett., 5, 1047-1050, 1978.

Baumjohann, W. G., Paschmann, G., and Lühr, H.: Characteristics of high-speed ion flows in the plasma sheet, J. Geophys. Res., 95, 3801-3809, 1990.
Block, L. and Fälthammar, C.-G.: The role of magnetic fieldaligned electric fields in auroral acceleration, J. Geophys. Res., 95, 5877-5888, 1990.

Borovsky, J. E.: Auroral arc thicknesses as predicted by various theories, J. Geophys. Res., 98, 6101-6138, 1993.

Carlson, C. W., McFadden, J. P., Ergun, R. E., Temerin, M., Peria, W., Mozer, F. S., Klumpar, D. M., Shelley, E. G., Peterson, W. K., Moebius, E., Elphic, R., Strangeway, R., Cattell, C., and Pfaff, R.: Fast observations in the downward auroral current region: Energetic upgoing electron beams, parallel potential drops, and ion heating, Geophys. Res. Lett., 25, 2017-2020, 1998.

Chen, L., Larson, D., Lin, R. P., and McCarthy, M., and Parks, G.: Multicomponent plasma distributions in the tail current sheet associated with substorms, Geophys. Res. Lett., 27, 843-846, 2000.

Dahlgren, H., Ivchenko, N., Sullivan, J., Lanchester, B. S., Marklund, G., and Whiter, D.: Morphology and dynamics of aurora at fine scale: first results from the ASK instrument, Ann. Geophys., 26, 1041-1048, 2008, http://www.ann-geophys.net/26/1041/2008/.

De Keyser, J.: Formation and evolution of subauroral ion drifts in the course of a substorm, J. Geophys. Res., 104, 12339-12350, 1999.

De Keyser, J.: Storm-time energetic particle penetration into the inner magnetosphere as the electromotive force in the subauroral ion drift current circuit, in: Magnetospheric Current Systems, edited by: Ohtani, S., no. 118 in Geophysical Monograph Series, pp. 261-265, AGU, 2000.

De Keyser, J., Roth, M., and Lemaire, J.: The magnetospheric driver of subauroral ion drifts, Geophys. Res. Lett., 25, 1625-1628, 1998.

Deminov, M. G. and Shubin, V. N.: Electric field effects in the nighttime subauroral F region, Geomagn. Aer., 28, 348-353, 1988.

Echim, M. M., Roth, M., and De Keyser, J.: Sheared magnetospheric plasma flows and discrete auroral arcs: a quasi-static coupling model, Ann. Geophys., 25, 317-330, 2007, http://www.ann-geophys.net/25/317/2007/.

Echim, M. M., Roth, M., and De Keyser, J.: Ionospheric feedback effects on the quasi-stationary coupling between LLBL and postnoon/evening discrete auroral arcs, Ann. Geophys., 26, 913-928, 2008 , http://www.ann-geophys.net/26/913/2008/.

Echim, M. M., Maggiolo, R., Roth, M., and De Keyser, J.: A magnetospheric generator driving ion and electron acceleration and electric currents in a discrete auroral arc observed by Cluster and DMSP, Geophys. Res. Lett., 36, L12111, doi:10.1029/2009GL038 343, 2009.

Ejiri, M., Hoffman, R. A., and Smith, P. H.: Energetic particle penetrations into the inner magnetosphere, J. Geophys. Res., 85, 653663, 1980.

Evans, D. S.: Precipitating electron fluxes formed by a magnetic field-aligned potential difference, J. Geophys. Res., 79, 28532858, 1974.

Feldstein, Y. I. and Galperin, Y. I.: The auroral luminosity structure in the high-latitude upper atmosphere: Its dynamics and relationship to the large-scale structure of the Earth's magnetosphere, Rev. Geophys., 23, 217-275, 1985.

Feldstein, Y. I., Gromova, L. I., Woch, J., Sandahl, I., Blomberg, 
L., Marklund, G., and Meng, C.-I.: Structure of the auroral precipitation region in the dawn sector: relationship to convection reversal boundaries and field-aligned currents, Ann. Geophys., 19, 495-519, 2001,

http://www.ann-geophys.net/19/495/2001/.

Figueiredo, S., Karlsson, T., and Marklund, G. T.: Investigation of subauroral ion drifts and related field-aligned currents and ionospheric Pedersen conductivity distribution, Ann. Geophys., 22, 923-934, 2004,

http://www.ann-geophys.net/22/923/2004/.

Figueiredo, S., Marklund, G. T., Karlsson, T., Johansson, T., Ebihara, Y., Ejiri, M., Ivchenko, N., Lindqvist, P.-A., Nilsson, H., and Fazakerley, A.: Temporal and spatial evolution of discrete auroral arcs as seen by Cluster, Ann. Geophys., 23, 2531-2557, 2005 ,

http://www.ann-geophys.net/23/2531/2005/.

Filippov, V. M., Shestakova, L. V., and Galperin, Y. I.: Belt of fast ion drift in the subauroral F-region and its manifestation in the structure of the high-latitude ionosphere, Ann. Geophys., 22, 923-934, 1984.

Filippov, V. M., Reshetnikov, D. D., Khalipov, V. L., Solov'ev, V. S., Stepanov, A. E., Galperin, Y. I., and Mulyarchuk, T. M.: Coordinated measurements of narrow troughs of ionization in the Fregion: Groundbased and satellite methods, Kosm. Issled., 27, 568-584, 1989.

Foster, J. C., Buonsanto, M. J., Mendillo, M., Nottingham, D., Rich, F. J., and Denig, W.: Coordinated stable auroral red arc observations: Relationship to plasma convection, J. Geophys. Res., 99, 11429-11439, 1994.

Foster, J. C., Rideout, W., Sandel, B., Forrester, W. T., and Rich, F. J.: On the relationship of SAPS to storm-enhanced density, J. Atmos. Solar-Terr. Phys., 69, 303-313, doi:10.1016/j.jastp.2006. 07.021, 2007.

Fridman, M. and Lemaire, J.: Relationship between auroral electron fluxes and field-aligned electric potential differences, J. Geophys. Res., 85, 664-670, 1980.

Galperin, Y. I. and Feldshtein, Y. I.: The diffuse auroral zone, the discrete auroral oval, and diffuse luminescence poleward of the oval in the night-time sector as a projection of plasma domains in the magnetotail, Kosm. Issled., 27, 890-901, 1989.

Galperin, Y. I., Ponomarev, V. N., and Zosimova, A. G.: Direct measurements of ion drift velocity in the upper atmosphere during a magnetic storm, Kosm. Issled., 11, 273-282, 1973.

Galperin, Y. I., Khalipov, V. L., and Filippov, V. M.: Signature of rapid subauroral ion drifts in the high-latitude ionosphere structure, Ann. Geophys., 4, 145-154, 1986.

Goldstein, J., Sandel, B. R., Hairston, M. R., and Reiff, P. H.: Control of plasmaspheric dynamics by both convection and subauroral polarization stream, Geophys. Res. Lett., 30, 2243, doi: 10.1029/2003GL018390, 2003.

Goldstein, J., Burch, J. L., and Sandel, B. R.: Magnetospheric model of subauroral polarization stream, J. Geophys. Res., 110, A09222, doi:10.1029/2005JA011135, 2005.

Gurgiolo, C., Sandel, B. R., Perez, J. D., Mitchell, D. G., Pollock, C. J., and Larsen, B. A.: Overlap of the plasmasphere and ring current: Relation to subauroral ionospheric heating, J. Geophys. Res., 110, A12217, doi:10.1029/2004JA010986, 2005.

Hamrin, M., Norqvist, P., Rönnmark, K., and Fellgård, D.: The importance of solar illumination for discrete and diffuse aurora,
Ann. Geophys., 23, 3481-3486, 2005, http://www.ann-geophys.net/23/3481/2005/.

Hamrin, M., Marghitu, O., Rönnmark, K., Klecker, B., André, M., Buchert, S., Kistler, L. M., McFadden, J., Rme, H., and Vaivads, A.: Observations of concentrated generator regions in the nightside magnetosphere by Cluster/FAST conjunctions, Ann. Geophys., 24, 637-649, 2006, http://www.ann-geophys.net/24/637/2006/.

Harel, M., Wolff, R. A., Reiff, P. H., and Spiro, R. W.: Quantitative simulation of a magnetospheric substorm. 1. Model logic and overview, J. Geophys. Res., 86, 2217-2241, 1981.

Hoch, R. J. and Lemaire, J.: Stable auroral red arcs and their importance for the physics of the plasmapause region, Ann. Geophys. 31, 105-110, 1974.

Hultqvist, B.: Downward ion acceleration at auroral latitudes: cause of parallel electric field, Ann. Geophys., 20, 1117-1136, 20022, http://www.ann-geophys.net/20/1117/20022/.

Johansson, T., Karlsson, T., Marklund, G., Figueiredo, S., Lindqvist, P.-A., and Buchert, S.: A statistical study of intense electric fields at 4-7 $R_{E}$ geocentric distance using Cluster, Ann. Geophys., 23, 2579-2588, 2005,

http://www.ann-geophys.net/23/2579/2005/.

Johansson, T., Marklund, G., Karlsson, T., Liléo, S., Lindqvist, P.A., Marchaudon, A., Nilsson, H., and Fazakerley, A.: On the profile of intense high-altitude auroral electric fields at magnetospheric boundaries, Ann. Geophys., 24, 1713-1723, 2006, http://www.ann-geophys.net/24/1713/2006/.

Johansson, T., Marklund, G., Karlsson, T., Liléo, S., Lindqvist, P.A., Nilsson, H., and Buchert, S.: Scale sizes of intense auroral electric fields observed by Cluster, Ann. Geophys., 25, 24132425, 2007, http://www.ann-geophys.net/25/2413/2007/.

Johansson, T., Bonnell, J. W., Cully, C., Donovan, E., Raeder, J., Eriksson, S., Andersson, L., Ergun, R. E., Angelopoulos, V., McFadden, J., Glassmeier, K.-H., and Mann, I.: Observation of an inner magnetosphere electric field associated with a BBF-like flow and PBIs, Ann. Geophys., 27, 1489-1500, 2009, http://www.ann-geophys.net/27/1489/2009/.

Karlsson, T., Marklund, G. T., Blomberg, L. G., and Mälkki, A.: Subauroral electric fields observed by the Freja satellite: A statistical study, J. Geophys. Res., 103, 4327-4341, 1998.

Knight, L.: Parallel electric fields, Planet. Space Sci., 21, 741-750, 1973.

Knudsen, D. J.: Structure, acceleration, and energy in auroral arcs and the role of Alfvén waves, Space Sci. Rev., 95, 501-511, 2001.

Knudsen, D. J., Donovan, E. F., L., C. L., Jackel, B., and Shaw, W. D.: Width and structure of mesoscale optical auroral arcs, Geophys. Res. Lett., 28, 705-708, 2001.

Kullen, A., Buchert, S., Karlsson, T., Johansson, T., Lileo, S., Eriksson, A., Nilsson, H., Marchaudon, A., and Fazakerley, A. N.: Plasma transport along discrete auroral arcs and its contribution to the ionospheric plasma convection, Ann. Geophys., 26, 32793293, 2008, http://www.ann-geophys.net/26/3279/2008/.

Lee, D.-H., Lysak, R. L., and Song, Y.: Generation of field-aligned currents in the near-Earth magnetotail, Geophys. Res. Lett., 28, 1883-1886, 2001.

Lemaire, J. and Scherer, M.: Simple model for an ion-exosphere in 
an open magnetic field, Phys. Fluids, 14, 1683-1694, 1971.

Lemaire, J. and Scherer, M.: Plasma sheet particle precipitation: A kinetic model, Planet. Space Sci., 21, 281-289, 1973.

Lemaire, J. F., Roth, M., and De Keyser, J.: High altitude electrostatic fields driving subauroral ion drifts, in: Magnetospheric Research with Advanced Techniques, edited by: Xu, R. L. and Lui, A. T. Y., pp. 61-64, Elsevier Science Publishers B. V., 1998.

Liléo, S., Marklund, G. T., Karlsson, T., Johansson, T., Lindqvist, P.-A., Marchaudon, A., Fazakerley, A., Mouikis, C., and Kistler, L. M.: Magnetosphere-ionosphere coupling during periods of extended high auroral activity: a case study, Ann. Geophys., 26, 583-591, 2008,

http://www.ann-geophys.net/26/583/2008/.

Liou, K., Newell, P. T., Meng, C.-I., Brittnacher, M., and Parks, G.: Synoptic auroral distribution: A survey using Polar ultraviolet imagery, J. Geophys. Res., 102, 27197-27205, 1997.

Lühr, H., Warnecke, J., Zanetti, L. J., Lindqvist, P. A., and Hughes, T. J.: Fine structure of field-aligned current sheets deduced from spacecraft and ground-based observations: Initial Freja results, Geophys. Res. Lett., 21, 1883-1886, 1994.

Lundin, R. and Evans, D.: Boundary layer plasmas as a source for high-latitude, early afternoon, auroral arcs, Planet. Space Sci., 33, 1389-1406, 1985.

Lyons, L. R.: Generation of large-scale regions of auroral currents, electric potentials and precipitation by the divergence of the convection electric field, J. Geophys. Res., 85, 17-24, 1980.

Lyons, L. R.: Discrete aurora as the direct result of an inferred high altitude generating potential distribution, J. Geophys. Res., 86, $1-8,1981$.

Lyons, L. R. and Walterscheid, R. L.: Feedback between neutral winds and auroral arc electrodynamics, J. Geophys. Res., 91, 13506-13512, 1986.

Lysak, R.: Coupling of the dynamic ionosphere to auroral flux tubes, J. Geophys. Res., 91, 7047-7056, 1986.

Lysak, R.: Feedback instability of the ionospheric resonant cavity, J. Geophys. Res., 96, 1553-1568, 1991.

Lysak, R. and Song, Y.: Energetics of the ionospheric feedback interaction, J. Geophys. Res., 107, 1160, doi:10.1029/2001JA000 308, 2002.

Marghitu, O., Hamrin, M., Klecker, B., Vaivads, A., McFadden, J., Buchert, S., Kistler, L. M., Dandouras, I., André, M., and Rème, H.: Experimental investigation of auroral generator regions with conjugate Cluster and FAST data, Ann. Geophys., 24, 619-635, 2006 , http://www.ann-geophys.net/24/619/2006/.

Marklund, G., Blomberg, L., Fälthammar, C.-G., and Lindqvist, P.A.: On intense diverging electric fields associated with black aurora, Geophys. Res. Lett., 21, 1859-1862, 1994.

Marklund, G., Blomberg, L., Flthammar, C.-G., Lindqvist, P.-A., and Eliasson, L.: On the occurrence and characteristics of intense low-altitude electric fields observed by Freja, Ann. Geophys., 13, 704-712, 1995, http://www.ann-geophys.net/13/704/1995/.

Marklund, G., Karlsson, T., and Clemmons, J.: On low-altitude particle acceleration and intense electric fields and their relationship to black aurora, J. Geophys. Res., 102, 17509-17522, 1997.

Marklund, G., Ivchenko, N., Karlsson, T., Fazakerley, A., Dunlop, M., Lindqvist, P.-A., Buchert, S., Owen, C., Taylor, M., Vaivads, A., Carter, P., André, M., and Balogh, A.: Temporal evolution of the electric field accelerating electrons away from the auroral ionosphere, Nature, 414, 724-727, 2001.

McIlwain, C. E.: Substorm injection boundaries, in: Magnetospheric Physics, edited by: McCormack, B. M., pp. 143-154, D. Reidel, Norwell, Mass., 1974.

Moffett, R. J., Ennis, A. E., Bailey, G. J., Heelis, R. A., and Brace, L. H.: Electron temperatures during rapid subauroral ion drift events, Ann. Geophys., 16, 450-459, 1998, http://www.ann-geophys.net/16/450/1998/.

Newell, P. T. and Meng, C.-I.: Low altitude observations of dispersionless substorm plasma injections, J. Geophys. Res., 92, 10063-10072, 1987.

Newell, P. T., Meng, C.-I., and Lyons, K. M.: Suppression of discrete aurorae by sunlight, Nature, 381, 766-767, 1996.

Newman, A. L., Chiu, Y. T., and Cornwall, J. M.: Two-dimensional quasi-neutral description of particles and fields above discrete auroral arcs, J. Geophys. Res., 91, 3167-3176, 1986.

Ober, D. M., Horwitz, J. L., and Gallagher, D. L.: Formation of density troughs embedded in the outer plasmasphere by subauroral ion drift events, J. Geophys. Res., 102, 14595-14602, 1997.

Parks, G. K., Skoug, R. M., Spencer, S. L., McCarthy, M. P., Lin, R. P., Larson, D., McFadden, J., Rème, H., and Sanderson, T. R.: Ion beams observed in the near Earth plasma sheet region on May 10, 1996, Geophys. Res. Lett., 24, 975-978, 1997.

Parks, G. K., Chen, L. J., McCarthy, M. P., Larson, D., Lin, R. P., Phan, T., Rème, H., and Sanderson, T.: New observations of ion beams in the plasma sheet boundary layer, Geophys. Res. Lett., 25, 3285-3288, 1998.

Pierrard, V.: New model of magnetospheric current-voltage relationship, J. Geophys. Res., 101, 2669-2676, 1996.

Pierrard, V., Khazanov, G. V., and Lemaire, J. F.: Currentvoltage relationship, J. Atmos. Solar-Terr. Phys., 69, 2048-2057, doi:10.1016/j.jastp.2007.08.005, 2007.

Prakash, M. and Rankin, R.: Role of ionospheric effects and plasma sheet dynamics in the formation of auroral arcs, Space Sci. Rev., 95, 513-537, 2001.

Prölss, G. W.: Subauroral electron temperature enhancement in the nighttime ionosphere, Ann. Geophys., 24, 1871-1885, 2006, http://www.ann-geophys.net/24/1871/2006/.

Puhl-Quinn, P. A., Matsui, H., Mishin, E., Mouikis, C., Kistler, L., Khotyaintsev, Y., Déecréau, P. M. E., and Lucek, E.: Cluster and DMSP observations of SAID electric fields, J. Geophys. Res., 112, A05219, doi:10.1029/2006JA012 065, 2007.

Rich, F. J., Burke, W. J., Kelley, M. C., and Smiddy, M.: Observations of field-aligned currents in association with strong convection electric fields at subauroral latitudes, J. Geophys. Res., 85, 2335-2340, 1980.

Robinson, R., Vondrak, R., Miller, K., Dabbs, T., and Hardy, D.: On calculating ionospheric conductances from the flux and energy of precipitating electrons, J. Geophys. Res., 92, 2565-2569, 1987.

Rodger, A. S., Moffet, R. J., and Quegan, S.: The role of ion drift in the formation of ionisation troughs in the mid- and high-latitude ionosphere: A review, J. Atmos. Terr. Phys., 54, 1-30, 1992.

Rönnmark, K. and Hamrin, M.: Auroral electron acceleration by Alfvén waves and electrostatic field, J. Geophys. Res., 105, 25333-25344, 2000.

Roth, M., Evans, D. S., and Lemaire, J.: Theoretical structure of a magnetospheric plasma boundary: Application to the formation of discrete auroral arcs, J. Geophys. Res., 98, 11411-11423, 
1993.

Roth, M., De Keyser, J., and Kuznetsova, M.: Vlasov theory of the equilibrium structure of tangential discontinuities in space plasmas, Space Sci. Rev., 76, 251-317, 1996.

Sato, T.: A theory of quiet auroral arcs, J. Geophys. Res., 83, 10421048, 1978.

Schriver, D.: Particle simulation of the auroral zone showing parallel electric fields, waves, and plasma acceleration, J. Geophys. Res., 104, 14655-14670, 1999.

Shue, J.-H., Newell, P., Liou, K., and Meng, C.-I.: The quantitative relationship between auroral brightness and solar EUV Pedersen conductance, J. Geophys. Res., 106, 5883-5894, 2001.

Smiddy, M., Kelley, M. C., Burke, W., Rich, F., Sagalyn, R., Shuman, B., Hays, R., and Lai, S.: Intense poleward directed electric fields near the ionospheric projection of the plasmapause, Geophys. Res. Lett., 4, 543-546, 1977.

Southwood, D. J. and Wolf, R. A.: An assessment of the role of precipitation in magnetospheric convection, J. Geophys. Res., 83, 5227-5232, 1978.

Spiro, R. W., Heelis, R. H., and Hanson, W. B.: Rapid subauroral ion drifts observed by Atmospheric Explorer C, Geophys. Res. Lett., 6, 657-660, 1979.

Swift, D. W.: New perspectives on auroral morphology, Space Sci. Rev., 95, 489-500, 2001.

Temerin, M. and Carlson, C.: Current-voltage relationship in the downward auroral current region, Geophys. Res. Lett., 25, 23652368, 1998.

Vaivads, A., André, M., Buchert, S., Eriksson, A. I., Olsson, A., Wahlund, J.-E., Janhunen, P., Marklund, G., Kistler, L. M., Mouikis, C., Winningham, D., Fazakerley, A., and Newell, P.: What high altitude observations tell us about the auroral acceleration: A Cluster/DMSP conjunction, Geophys. Res. Lett., 30, 1106, doi:10.1029/2002GL016 006, 2003.
Vedin, J. and Rönnmark, K.: A linear auroral current-voltage relation in fluid theory, Ann. Geophys., 22, 1719-1728, 2004, http://www.ann-geophys.net/22/1719/2004/.

Vedin, J. and Rönnmark, K.: Electrostatic potentials in the downward auroral current region, J. Geophys. Res., 110, A08207, doi:10.1029/2005JA011083, 2005.

Voiculescu, M. and Roth, M.: Eastward sub-auroral ion drifts or ASAID, Ann. Geophys., 26, 1955-1963, 2008, http://www.ann-geophys.net/26/1955/2008/.

Walterscheid, R. L. and Lyons, L. R.: The neutral circulation in the vicinity of a stable auroral arc, J. Geophys. Res., 97, 1948919499, 1992.

Walterscheid, R. L., Lyons, L. R., and Taylor, E.: The perturbed neutral circulation in the vicinity of a symmetric stable auroral arc, J. Geophys. Res., 90, 12235-12248, 1985.

Yeh, H.-C., Foster, J. C., Rich, F., and Swider, W.: Storm time electric field penetration observed at mid-latitude, J. Geophys. Res., 96, 5707-5721, 1991.

Zhu, L., Sojka, J. J., Schunk, R. W., and Crain, D. J.: A timedependent model of polar cap arcs, J. Geophys. Res., 98, 61396150, 1993.

Zhu, L., Sojka, J. J., and Schunk, R. W.: Active ionospheric role in small-scale aurora structuring, J. Atmos. Solar-Terr. Phys., 67, 687-700, 2005. 